\title{
Rotaxanes and pseudorotaxanes with threads containing pyridinium units
}

\author{
Malgorzata Deska, Jolanta Kozlowska, and Wanda Sliwa* \\ Jan Dlugosz University, Institute of Chemistry, Environmental Protection and Biotechnology, \\ 42-200 Czestochowa, Armii Krajowej 13/15 Street, Poland \\ E-mail:w.sliwa@ajd.czest.pl
}

\begin{abstract}
In this review, a continuation of an earlier one concerning rotaxanes with threads containing viologen units, the syntheses and properties of rotaxanes with threads bearing quaternary pyridinium units are described, along with their possible applications. In the first part rotaxanes containing bis(dipyridiniumyl)ethane unit in the thread are presented; they include species with stoppers incorporating metal complexes. The second part concerns rotaxanes formed by anion templation, they are divided into those involving the Grubbs RCM procedure for construction of a ring, and those employing rings built by condensation reactions. Then rotaxanes synthesized with the use of previously prepared rings are described. The third part deals with rotaxane molecular machines, especially those bearing mannosyl moieties. In the last part pseudorotaxanes containing crown ether based cryptands as rings, are shown.
\end{abstract}

Keywords: Association constants; crown ether; cryptand; interlocked structure; templation

\section{Table of Contents}

1. Introduction

2. Rotaxanes containing bis(dipyridiniumyl)ethane unit in the thread

2.1. Rotaxanes with conventional stoppers

2.2. Rotaxanes with stoppers incorporating metal complexes

3. Rotaxanes formed by anion templation

3.1. Rotaxanes with rings built by Grubbs RCM procedure

3.2. Rotaxanes with rings built by condensation reactions

3.3. Rotaxanes with previously prepared rings

4. Rotaxane-based molecular machines

5. Pseudorotaxanes containing cryptands as rings

6. Conclusions

7. Acknowledgements

References

\section{Introduction}

Rotaxanes, ${ }^{1-4}$ as well as catenanes, ${ }^{5-7}$ daisy chains, ${ }^{8,9}$ and molecular knots, ${ }^{10,11}$ belong to mechanically interlocked molecules; ${ }^{12,13}$ in recent years investigation of these species has developed rapidly due to their valuable properties and applications in molecular electronics and in design of smart novel materials.

Rotaxanes are of interest in the nanotechnology field for the construction of molecular machines and devices; $;^{14,15}$ also pseudorotaxanes, ${ }^{16-18}$ polypseudorotaxanes ${ }^{19,20}$ and polyrotaxanes $^{21-23}$ deserve an attention. Rotaxanes based on cyclodextrins, ${ }^{24-27}$ calixarenes, ${ }^{28,29}$ 
and cucurbiturils ${ }^{30,31}$ are also a topic of many recent reports; the CD-based rotaxanes ${ }^{32,33}$ and CD-based polyrotaxanes ${ }^{34-36}$ are now intensively studied (CD stands for cyclodextrin).

New species, i.e. rotaxanes and pseudorotaxanes containing pillararene units as rings, have recently been developed. Pillararenes ${ }^{8,37-41}$ belong to a new class of cyclophanes, they are $\left[1_{n}\right]$ paracyclophanes composed of 1,4-hydroquinones linked by methylene bridges in their 2,5positions; formally they are similar to calixarenes. It has been found that pillararenes may form rotaxanes and pseudorotaxanes, ${ }^{42,43}$ in which threads may be $e . g$. viologen derivatives ${ }^{37,39}$

This review is a continuation of an earlier review dealing with rotaxanes with threads containing viologen units ${ }^{44}$ and of our former papers dealing with interlocked structures of quaternary azaaromatics. ${ }^{45,46}$ In view of our interest in quaternary azaaromatics, and moreover taking into account the enormous amount of reports on rotaxanes with threads containing pyridinium units, in the present review we describe only their selected examples.

\section{Rotaxanes containing bis(dipyridiniumyl)ethane unit in the thread}

\subsection{Rotaxanes with conventional stoppers}

Syntheses of two classes of rotaxanes, namely those with $t$-butylbenzyl stoppers and those with $t$ butylbenzoate stoppers have been performed. Pseudorotaxanes $\mathbf{1}$ and $\mathbf{2}$ containing crown ethers A, B or $\mathbf{N}$ were converted into rotaxanes $\mathbf{3}$ and $\mathbf{4}$, respectively, using two methods of stoppering: for $\mathbf{1}$ the alkylation of terminal pyridine units by $t$-butylbenzyl groups, and for $\mathbf{2}$ the esterification of terminal benzyl alcohol by $p$ ( $t$-butyl)benzoate groups (Scheme1). ${ }^{47}$

- For 1: the thread $\mathbf{5}$ was treated with crown ethers $\mathbf{A}, \mathbf{B}$ or $\mathbf{N}$ affording pseudorotaxanes $\mathbf{1}$ which upon alkylation with 4-(t-butyl)benzyl bromide, followed by $\mathrm{Br}^{-} \rightarrow \mathrm{CF}_{3} \mathrm{SO}_{3}{ }^{-}$ion exchange yielded rotaxanes $3^{48}$

- For 2: pyridine 6 was treated with 1,2-dibromoethane, followed by $\mathrm{NaBF}_{4}$, to give the thread 7 which with crown ethers afforded pseudorotaxanes 2 . The subsequent reaction of 2 with 4-( $t$-butyl)benzoic anhydride gave rise to rotaxanes 4 . $^{49}$

The results of X-ray crystallography have shown that in rotaxanes $\mathbf{3} \cdot \mathbf{B}, \mathbf{3} \cdot \mathbf{N}$ and $\mathbf{4} \cdot \mathbf{B}$ the threads exist in the low energy anti conformation, and the crown ethers adopt the S-shaped conformation.

The acid-base driven molecular shuttle consisting of two [2] rotaxanes $\mathbf{8}^{2+}$ and $\mathrm{H} \cdot \mathbf{8}^{3+}$ has been synthesized (Scheme 2). Both rotaxanes contain benzylanilinium and 1,2bis(dipyridiniumyl) ethane recognition sites. ${ }^{50}$

In $8^{2+}$, in $\mathrm{CD}_{2} \mathrm{Cl}_{2}$ the ring resides at the bis(dipyridiniumyl)ethane site. The protonation of $\mathbf{8}^{2+}$ into $\mathrm{H} \cdot \mathbf{8}^{3+}$ results in the moving of the ring to the benzylanilinium recognition site. This behavior shows that this molecular shuttle acts as a bistable ON/OFF switch.

The addition of a base such as $\mathrm{Et}_{3} \mathrm{~N}$ results in the return of the ring to the bis(dipyridiniumyl)ethane site affording the original rotaxane $\mathbf{8}^{\mathbf{2 +}}$, and the subsequent addition of an acid $\mathrm{CF}_{3} \mathrm{SO}_{3} \mathrm{H}$ brings about a repetition of the process. The switching between $\mathbf{8}^{2+}$ and $\mathrm{H} \cdot \mathbf{8}^{3+}$ is accompanied by a visible color change. 


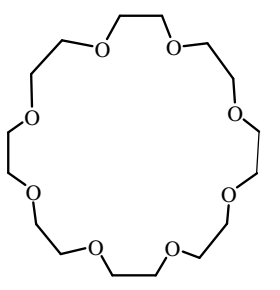

A

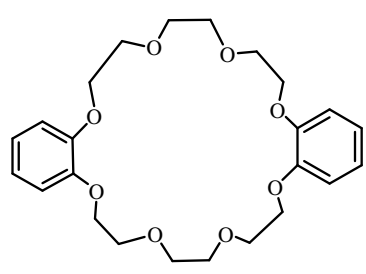

B

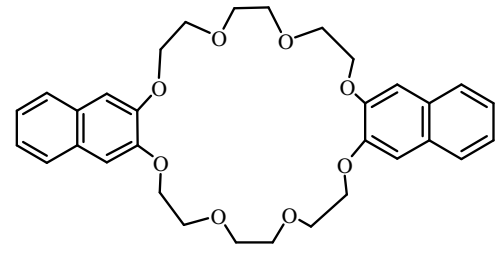

$\mathbf{N}$
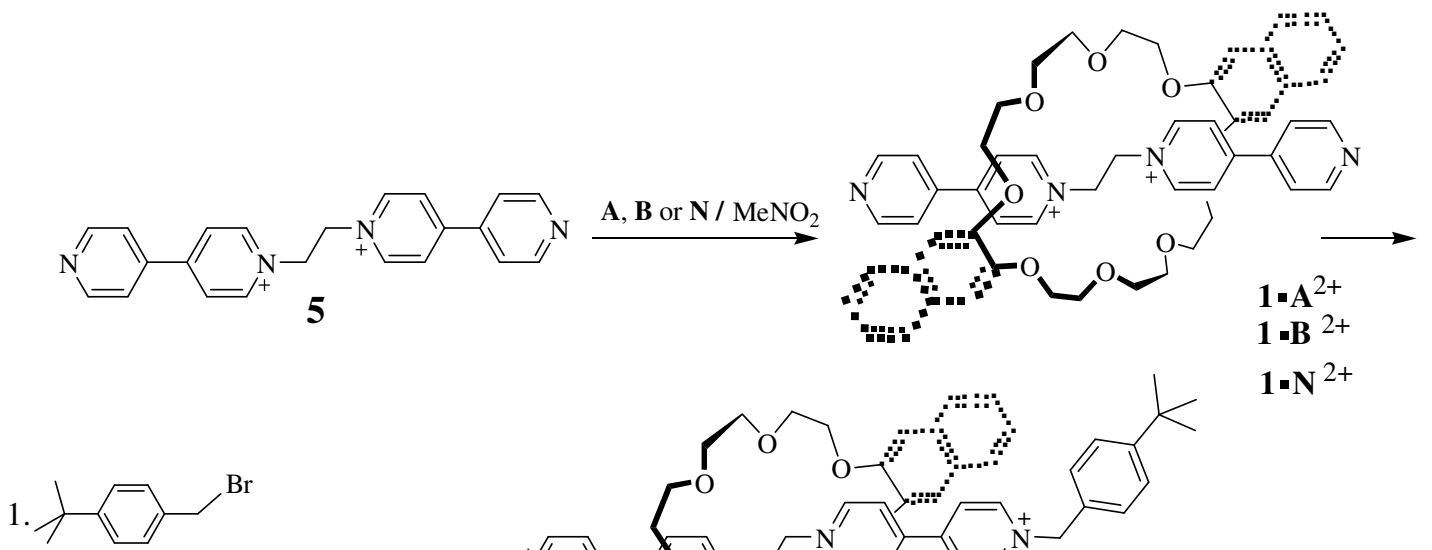

2. $\mathrm{CF}_{3} \mathrm{SO}_{3}^{-} \mathrm{Na}^{+}$
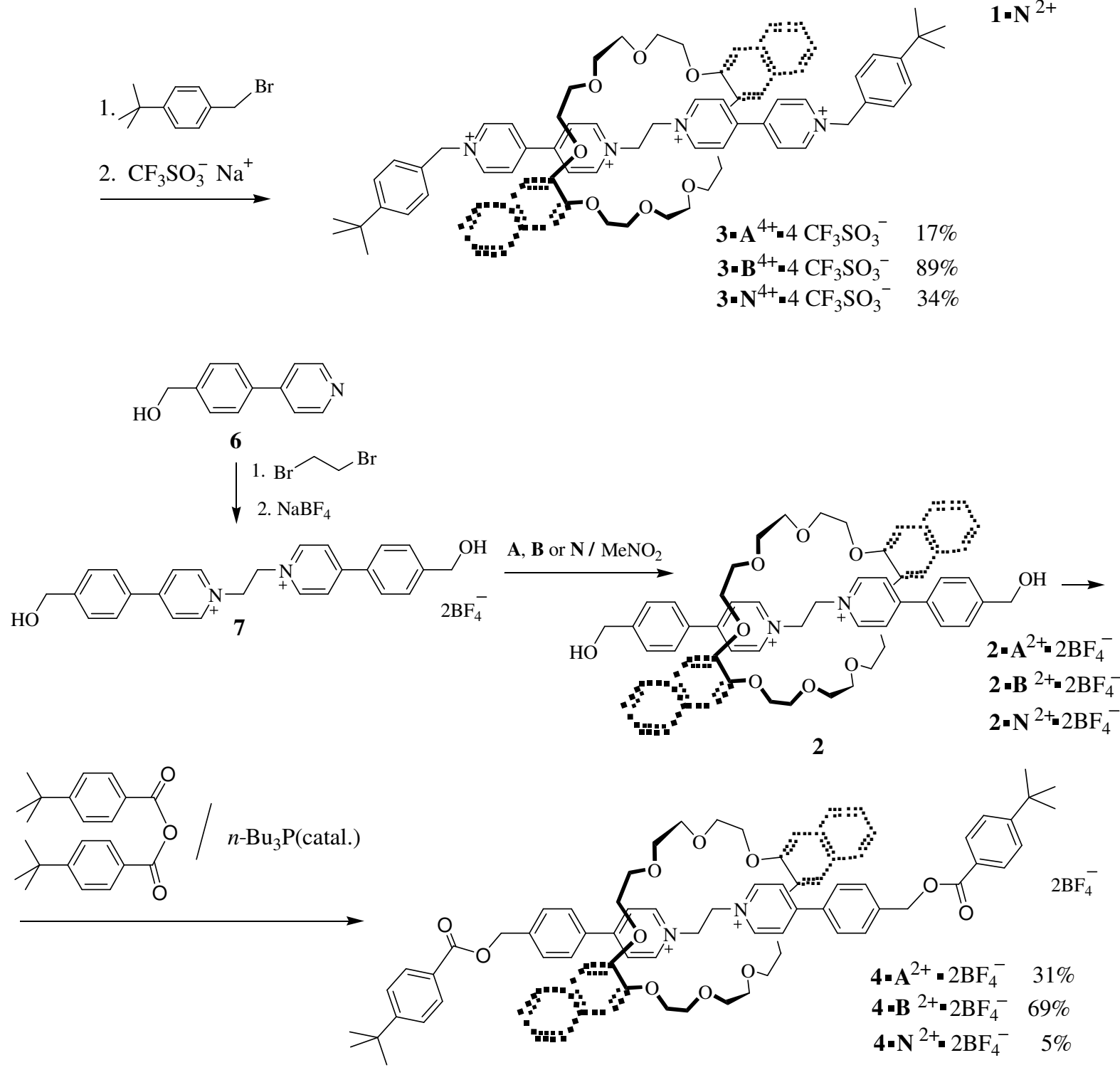

\section{Scheme 1}

The molecular shuttle $\mathbf{9}^{2+}$ similarly acting as $\mathbf{8}^{2+}$ contains a 9-methylanthracenyl group instead of the 3,5-bis(trifluoromethyl)benzyl group; this shuttling can be monitored by a change in fluorescence intensity. ${ }^{50}$ 

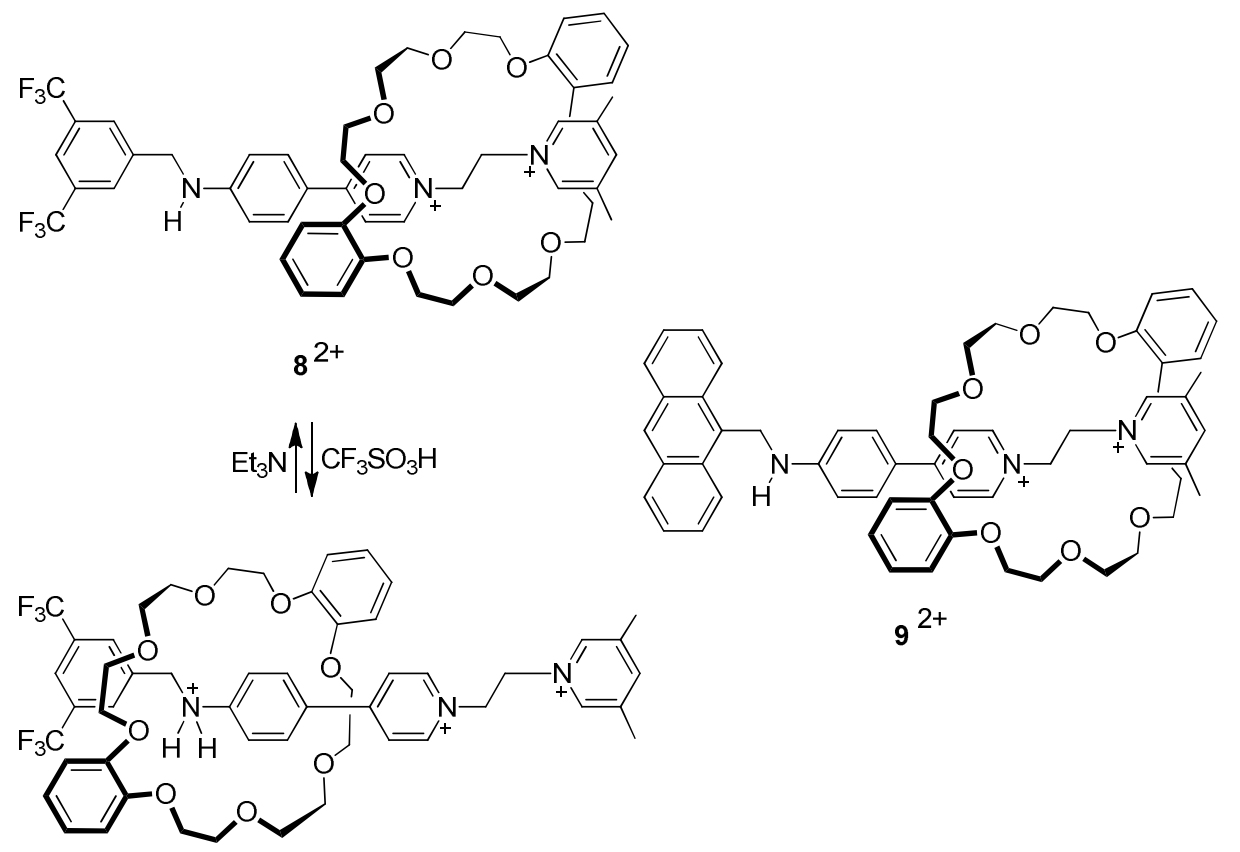

$$
\mathrm{H} \cdot 8^{3+}
$$

\section{Scheme 2}

In the study of rotaxanes with large macrocyclic rings, ${ }^{51,52}$ the [2] rotaxanes $\mathbf{1 0} \cdot 4 \mathrm{PF}_{6}$ and $11 \cdot 2 \mathrm{H} \cdot 4 \mathrm{PF}_{6}$ have been synthesized using threading-followed-by-stoppering procedure. In 10. $4 \mathrm{PF}_{6}$ the thread contains four pyridinium stations and in $11 \cdot 2 \mathrm{H} \cdot 4 \mathrm{PF}_{6}$ the thread contains two dialkylammonium and two pyridinium stations (Scheme 3 ). ${ }^{53}$

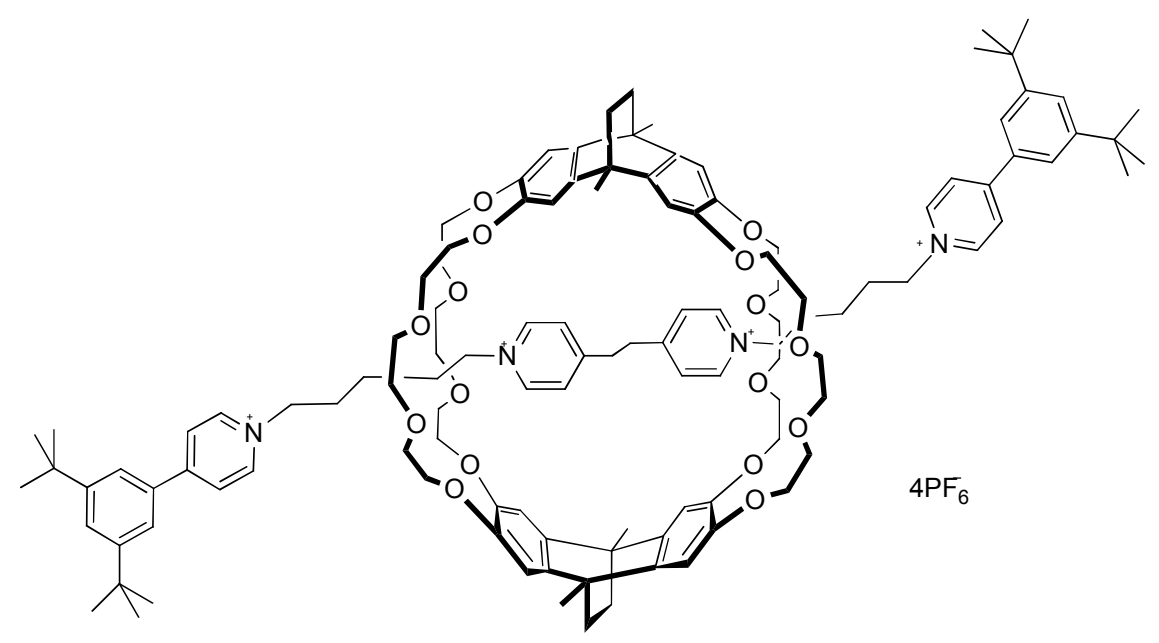

10. $4 \mathrm{PF}_{6}$

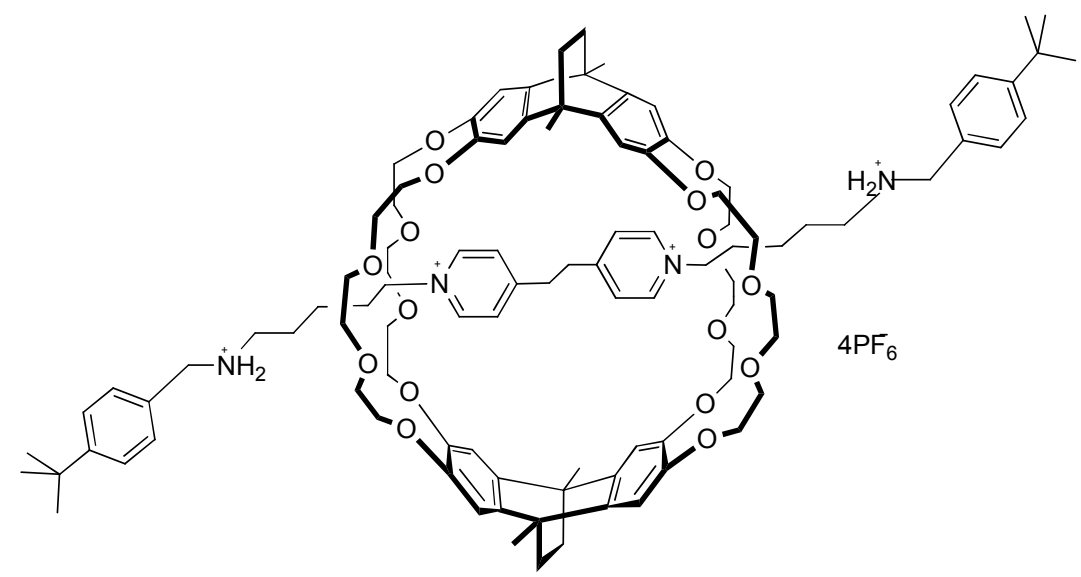

11. $2 \mathrm{H} \cdot 4 \mathrm{PF}_{6}$ 

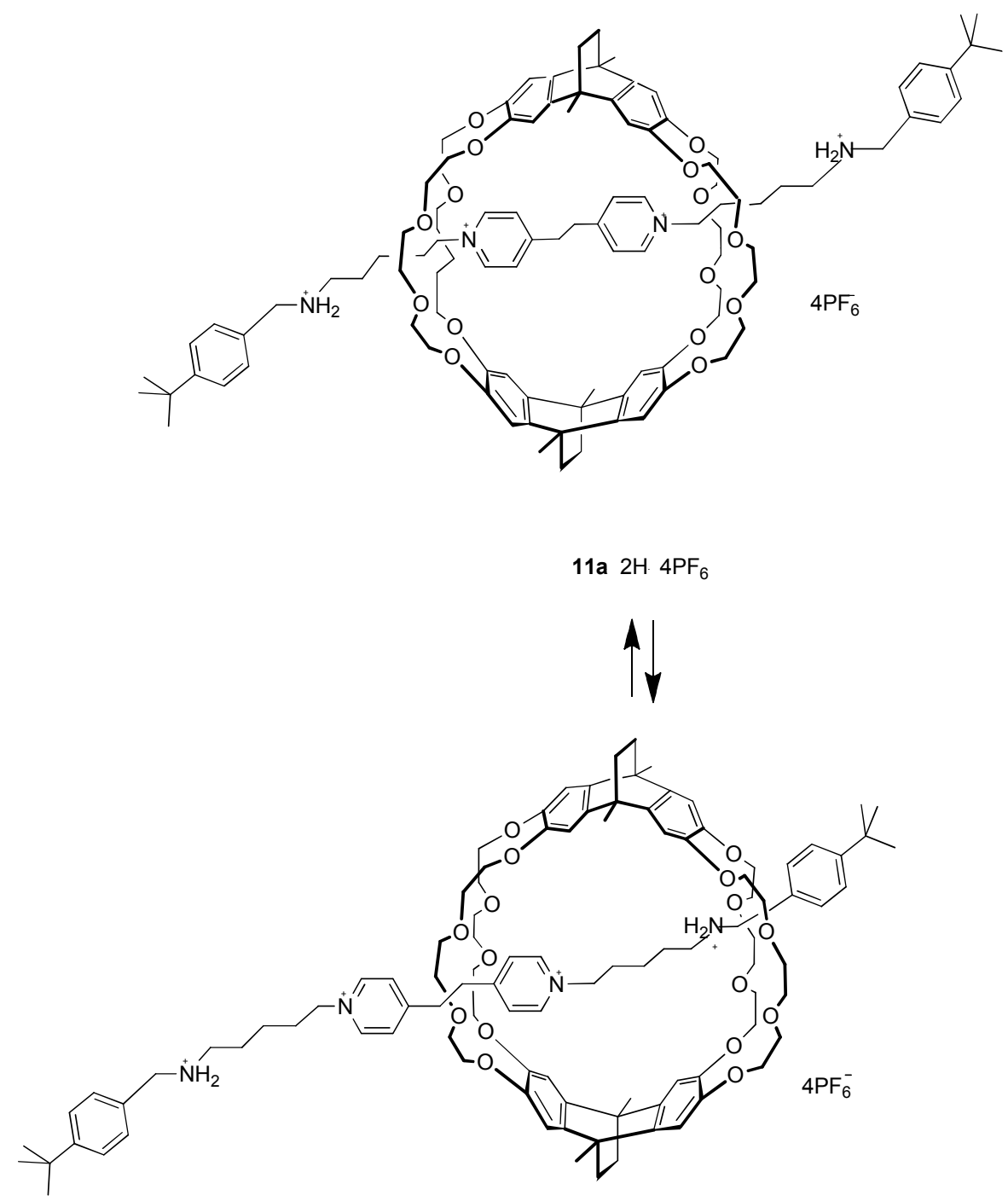

11b. $2 \mathrm{H} \cdot 4 \mathrm{PF}_{6}$

\section{Scheme 3}

The ${ }^{1} \mathrm{HNMR}$ results have shown that rotaxane $\mathbf{1 1} \cdot 2 \mathrm{H} \cdot 4 \mathrm{PF}_{6}$ in $\mathrm{CD}_{3} \mathrm{NO}_{2}$ is a $1: 4$ mixture of translational isomers $\mathbf{a}$ and $\mathbf{b}$. It was found that the ratio of translational isomers $\mathbf{a}$ and $\mathbf{b}$ depends on the solvent polarity. In polar solvents, such as $\mathrm{CD}_{3} \mathrm{CN}$, the $\pi$-stacking is favored over hydrogen-bonding interactions, and the symmetrical translational isomer a exists exclusively. However, in $\mathrm{CD}_{3} \mathrm{NO}_{2}$, which is less disruptive of hydrogen bonds than $\mathrm{CD}_{3} \mathrm{CN}$, the unsymmetrical isomer $\mathbf{b}$ is predominant. Conversion $\mathbf{a} \rightarrow \mathbf{b}$ may also take place upon treatment with TFA; the process is reversible, addition of $\mathrm{Et}_{3} \mathrm{~N}$ leads to the inverse, i.e. $\mathbf{b} \rightarrow \mathbf{a}$ process.

The ratio of translational isomers $\mathbf{a}$ and $\mathbf{b}$ is also influenced by the kind of counterions. When the $\mathrm{CD}_{3} \mathrm{NO}_{2}$ solution of $\mathbf{1 1} \cdot 2 \mathrm{H} \cdot 4 \mathrm{PF}_{6}$ was treated with $\mathrm{Bu}_{4} \mathrm{NCl}$, the ring was shifted to the centre of the rotaxane, to give $11 \mathrm{a} \cdot 2 \mathrm{H} \cdot 4 \mathrm{Cl}$. The subsequent addition of $\mathrm{AgPF}_{6}$ in order to remove the chloride anions from the solution affords the original 1:4 mixture of $\mathbf{a}$ and $\mathbf{b}$, i.e. $\mathbf{1 1 b} \cdot 2 \mathrm{H} \cdot 4 \mathrm{PF}_{6}$ is formed and the translational isomer $\mathbf{b}$ prevails.

The obtained results show that the above molecular switch can be controlled by three ways: by changing solvent polarity, by addition acid/basic reagents $\left(\mathrm{TFA} / \mathrm{Et}_{3} \mathrm{~N}\right)$ or by exchange of counterions $\left(\mathrm{PF}_{6}^{-} \rightarrow \mathrm{Cl}^{-}\right)$.

\subsection{Rotaxanes with stoppers incorporating metal complexes}

Recently $N$-heterocyclic carbenes have been widely investigated; they are used in construction of three-dimensional structures ${ }^{54,55}$ and of metalla-macrocycles. ${ }^{56,57}$

As an example of rotaxanes stoppered by palladium $N$-heterocyclic carbene may serve [2] rotaxane 12, obtained from bis(dipyridiniumyl)ethane 5 and dibenzo[24]crown-8 (DB24C8) in the presence of dimeric Pd(II)benzimidazolin-2-ylidene complex $\left[\operatorname{PdBr}_{2}\left(i-\mathrm{Pr}_{2}-\text { bimy }\right)\right]_{2}{ }^{58,59}$

The X-ray analysis of $\mathbf{1 2}$ shows a crystallographically imposed inversion symmetry; the $\pi-\pi$ stacking interactions between the electron deficient pyridinium units of the thread and electron- 
rich catechol units of the ring result in the bending of the ring into the S-shape conformation (Scheme 4).
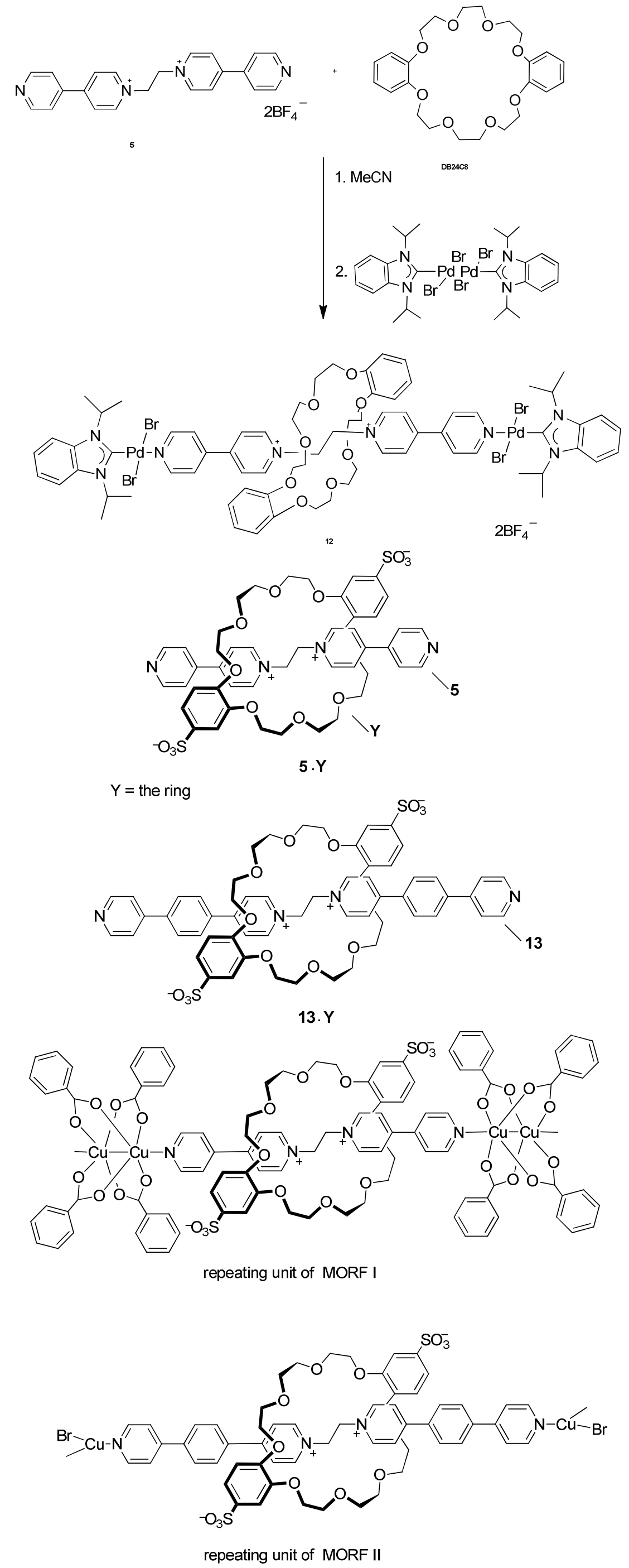
It was found that metal-organic rotaxane frameworks MORFs (i.e. MOFs containing [2]rotaxane as one of the organic linkers) may be constructed without the need for independent counterions. The elimination of counterions in MORFs is possible by combining neutral linkers with neutral metal nodes.

As examples may serve the neutral [2]pseudorotaxanes composed of bis(dipyridiniumyl)ethane as a thread and of disulfonated dibenzo-24 crown-8 ether $\mathbf{Y}$ as a ring. When they are combined with neutral metallic units such as $\mathrm{Cu}$ (II) benzoate paddlewheel or $\mathrm{Cu}(\mathrm{I}) \mathrm{Br}$, the linear coordination polymers are formed; they are neutral MORFs. ${ }^{60}$

The interaction of a dicationic thread with a dianionic ring not only affords a neutral linker, but strongly enhances the binding between the thread and the ring due to electrostatic attraction of pyridinium units with sulfonate groups. Such structure connected with a neutral metal complex able to propagate a polymeric framework yields an overall neutral MORF.

Two [2]pseudorotaxane ligands containing dications $\mathbf{5}$ and $\mathbf{1 3}$ as threads and dianion $\mathbf{Y}$ as a ring were obtained; they are $\mathbf{5 \cdot Y}$ and $\mathbf{1 3} \cdot \mathbf{Y}$, respectively; the thread $\mathbf{1 3}$ is an extended version of $\mathbf{5}$, differing from $\mathbf{5}$ by the presence of two inserted $p$-phenylene units.

Crystals of [2]pseudorotaxane $\left\{[\mathbf{5} \cdot \mathbf{Y}](\mathrm{MeOH})_{7}(\mathrm{DMF})\right\}$ were grown from a mixture of $\mathbf{5}\left[\mathrm{BF}_{4}\right]_{2}$ and $\left[\mathrm{Me}_{4} \mathrm{~N}\right]_{2}[\mathbf{Y}]$ in $\mathrm{MeOH} / \mathrm{DMF}$. In $\mathbf{5} \cdot \mathbf{Y}$ the electron-deficient pyridinium units of $\mathbf{5}$ are $\pi$-stacked with the electron-rich aromatic units of $\mathbf{Y}$; the resulting charge transfer absorption is visible by the appearance of the yellow color. The obtained [2]pseudorotaxane can act as a neutral linker for binding metal units to give MORFs.

For preparation of MORF, the $\mathrm{Cu}$ paddlewheel, i.e. copper(II) benzoate $\left[\mathrm{Cu}_{2}(\mathrm{BzO})_{4}\right]$ was used as a neutral metal node able for linear propagation. ${ }^{61}$ Combining $\mathbf{5}\left[\mathrm{BF}_{4}\right]_{2}$ with $\left[\mathrm{Me}_{4} \mathrm{~N}\right]_{2}[\mathbf{Y}]$ and $\left[\mathrm{Cu}_{2}(\mathrm{BzO})_{4}\left(\mathrm{H}_{2} \mathrm{O}\right)_{2}\right]$ in $\mathrm{MeOH} / \mathrm{DMF}$ afforded turquoise crystals of $\left\{\left[\mathrm{Cu}_{2}(\mathrm{BzO})_{4}(\mathbf{5} \cdot \mathbf{Y})\right](\mathrm{MeOH})_{2}(\mathrm{DMF})\right\}_{\mathrm{x}}$, i.e. MORF I. In this MORF the terminal pyridine groups of pseudorotaxane $\mathbf{5} \cdot \mathbf{Y}$ bind to the two coordination sites of the $\mathrm{Cu}$ (II) paddlewheel. The linear coordination polymer MORF I so formed is overall neutral.

In $\left\{\left[\mathrm{Cu}_{2}(\mathrm{BzO})_{4}(\mathbf{5} \cdot \mathbf{Y})\right]\right\}_{\mathrm{x}}$ the sulfonate groups of $\mathbf{Y}$ are localized close to one of the benzene rings of the $\mathrm{Cu}(\mathrm{II})$ paddlewheel; this close neighborhood may result in hydrogen bonding which would disturb the arrangement of the whole system. In order to overcome this inconvenience, the thread 13, longer than 5 was used to prepare MORF II. Such experiment combining $13\left[\mathrm{BF}_{4}\right]_{2}$ with $\left[\mathrm{Me}_{4} \mathrm{~N}\right]_{2} \mathbf{Y}$ and $\mathrm{CuBr}$ in $\mathrm{MeOH} / \mathrm{H}_{2} \mathrm{O}$ afforded yellow crystals of $\left\{[\mathrm{CuBr}(\mathbf{1 3} \cdot \mathbf{Y})]\left(\mathrm{H}_{2} \mathrm{O}\right)_{10}\right\}_{x}$, i.e. MORF II. In this MORF the terminal pyridine groups of pseudorotaxane $\mathbf{1 3} \cdot \mathbf{Y}$ bind to the two trigonal planar $\mathrm{Cu}(\mathrm{I})$ centres.

The above results are promising for the preparation of robust materials with interlocked components.

\section{Rotaxanes formed by anion templation}

In the study of rotaxanes the anion recognition attracts today a growing attention due to the crucial role of anions in biological and environmental processes, therefore many reports concerning this topic appear. ${ }^{62,63}$ It is important that for selective recognition of guests the rotaxanes should contain an appropriate reporter group providing their electrochemical or optical response.

The anion templation method, widely used for the synthesis of rotaxanes, will be described below. Syntheses of selected rotaxanes, performed by this method are divided here into three classes:

1) syntheses of rotaxanes with rings built by Grubbs RCM procedure,

2) syntheses of rotaxanes with rings built by condensation reactions, and

3) syntheses of rotaxanes with previously prepared rings. 


\subsection{Rotaxanes with rings built by Grubbs RCM procedure}

In the Grubbs ring closing metathesis (RCM) procedure the divinyl precursor of the ring of rotaxane is cyclized with the use of Grubbs second generation catalyst. Three examples $A-C$ of this method are shown below.

\section{Example A}

The redox-active rotaxane $\mathbf{1 4} \cdot \mathrm{PF}_{6}$ containing two ferrocene derivative units appended to the thread was synthesized with the aim to investigate its electrochemical sensing of anions in solution, having in view the redox-active properties of ferrocenes for the detection of anions. ${ }^{64,65}$ In this rotaxane the ferrocene pentaphenyl derivative units serve as redox-active species, and moreover they are stoppers.

The rotaxane $\mathbf{1 4} \cdot \mathrm{PF}_{6}$ was synthesized using the chloride template clipping, which was performed by treatment of $\mathbf{1 5} \cdot \mathrm{Cl}$ with bis-vinyl isophthalamide $\mathbf{1 6}$ serving as a precursor of the ring. This RCM process was carried out in the presence of Grubbs second generation catalyst. The formed rotaxane $\mathbf{1 4} \cdot \mathrm{Cl}$ upon anion exchange was converted into $14 \cdot \mathrm{PF}_{6}{ }^{66}$

The results of $\mathrm{X}$-ray analysis of $\mathbf{1 4} \cdot \mathrm{Cl}$ and $\mathbf{1 4} \cdot \mathrm{PF}_{6}$ have shown that:

In the structure of $\mathbf{1 4} \cdot \mathrm{Cl}$ the chloride anion is situated in the cavity of the rotaxane, and is held in place by hydrogen bonding to the pyridinium and isophthalamide clefts. Between the pyridinium unit and hydroquinone rings the $\pi-\pi$ stacking exists.

In the structure of $\mathbf{1 4} \cdot \mathrm{PF}_{6}$, formed after the removal of the chloride template from the rotaxane cavity, the $\mathrm{PF}_{6}{ }^{-}$counteranion is situated outside the rotaxane cavity and does not interact with the rotaxane structure. The anion exchange $\left(\mathrm{Cl}^{-} \rightarrow \mathrm{PF}_{6}^{-}\right)$did not influence the $\pi-\pi$ stacking between the pyridinium unit and hydroquinone rings, this $\pi-\pi$ stacking still remains in 14. $\mathrm{PF}_{6}$.

The anion recognition properties of rotaxane $\mathbf{1 4} \cdot \mathrm{PF}_{6}$ were examined by ${ }^{1} \mathrm{HNMR}$ titration experiments with tetrabutylammonium (TBA) salts of $\mathrm{Cl}^{-}, \mathrm{H}_{2} \mathrm{PO}_{4}^{-}, \mathrm{PhCOO}^{-}, \mathrm{HSO}_{4}^{-}$and $\mathrm{NO}_{3}^{-}$ anions. It was shown that upon removal of the chloride anion template, the rotaxane exhibits not only enhanced binding of chloride, but also the higher selectivity for chloride over the more basic oxoanions in the competitive solvent system $\mathrm{CDCl}_{3} / \mathrm{CD}_{3} \mathrm{OD}(1: 1)$. This behavior results from the fact that only chloride can bind inside the cavity of rotaxane; polyatomic oxoanions are too large for such penetration and therefore they are situated at the periphery of the cavity.

The investigation of electrochemical anion recognition by rotaxane $14 \cdot \mathrm{PF}_{6}$ has shown that it gave a characteristic electrochemical response with chloride in contrast to oxoanions $\mathrm{H}_{2} \mathrm{PO}_{4}^{-}$, $\mathrm{PhCOO}^{-}, \mathrm{HSO}_{4}^{-}$and $\mathrm{NO}_{3}^{-}$; for addition of chloride to rotaxane $\mathbf{1 4} \cdot \mathrm{PF}_{6}$ the maximum cathodic shift of the pentaphenylferrocene/pentaphenylferrocenium ${ }^{+} \mathrm{Pf} / \mathrm{Pf}^{+}$redox couple occurred at one equivalent of $\mathrm{Cl}^{-}$, whereas for other anions the maximum shift was observed at more equivalents of anions added (Scheme 5). This fact results from the strong binding of chloride anion inside the interlocked cavity of rotaxane. ${ }^{66}$

\section{Example B}

Another example of rotaxane formation by chloride anion templation and RCM is the synthesis of rotaxane $\mathbf{1 9} \cdot \mathrm{PF}_{6}$ bearing ferrocene moiety on the ring. The synthesis of $19 \cdot \mathrm{Cl}$ involves the reaction of the thread $17 \cdot \mathrm{Cl}$ with 18 , being a precursor of the ring; the process is carried out in the presence of Grubbs II catalyst in $\mathrm{CH}_{2} \mathrm{Cl}_{2}$. The ion exchange by treatment of 19. $\mathrm{Cl}$ with $\mathrm{NH}_{4} \mathrm{PF}_{6}$ afforded the desired rotaxane $19 \cdot \mathrm{PF}_{6} \cdot{ }^{67}$

The ${ }^{1} \mathrm{HNMR}$ titration results have shown that $\mathbf{1 9} \cdot \mathrm{PF}_{6}$ is selective for chloride anion over more basic oxoanions $\mathrm{H}_{2} \mathrm{PO}_{4}^{-}$, $\mathrm{PhCOO}^{-}$and $\mathrm{HSO}_{4}^{-}$. Very strong binding was found for $\mathbf{1 9} \cdot \mathrm{PF}_{6}$ and $\mathrm{TBACl}$ in $\mathrm{CD}_{3} \mathrm{CN},\left(K>10^{4} \mathrm{M}^{-1}\right)$.

It was observed that $\mathbf{1 9} \cdot \mathrm{PF}_{6}$ displays electrochemical recognition of $\mathrm{Cl}^{-}$; it was evidenced by a maximum cathodic shift response of the ferrocene/ferrocenium ${ }^{+} \mathrm{Fc} / \mathrm{Fc}^{+}$redox couple observed at equimolar concentrations of rotaxane and $\mathrm{Cl}^{-}$ion, while in the case of oxoanions an excess of their equivalents is necessary. 


\section{Example A}

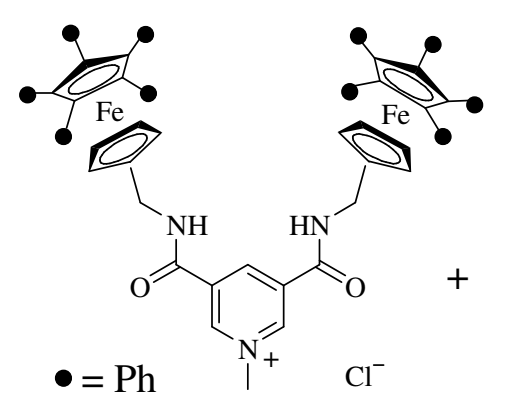

$15 \cdot \mathrm{Cl}$

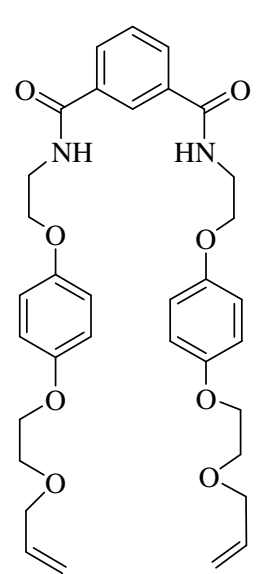

16

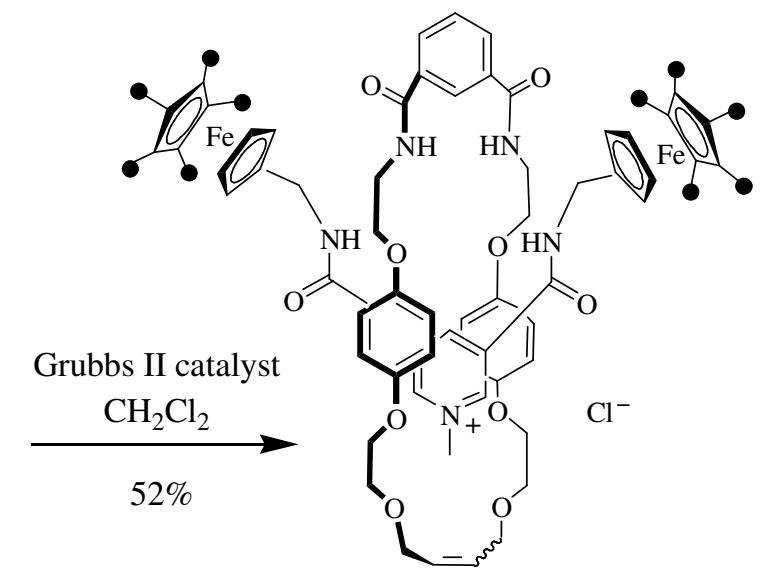

$\left.\begin{array}{l}\text { 14. } \mathrm{Cl} \\ \text { 14. } \mathrm{PF}_{6}\end{array}\right] \mathrm{NH}_{4} \mathrm{PF}_{6}$

\section{Example B}

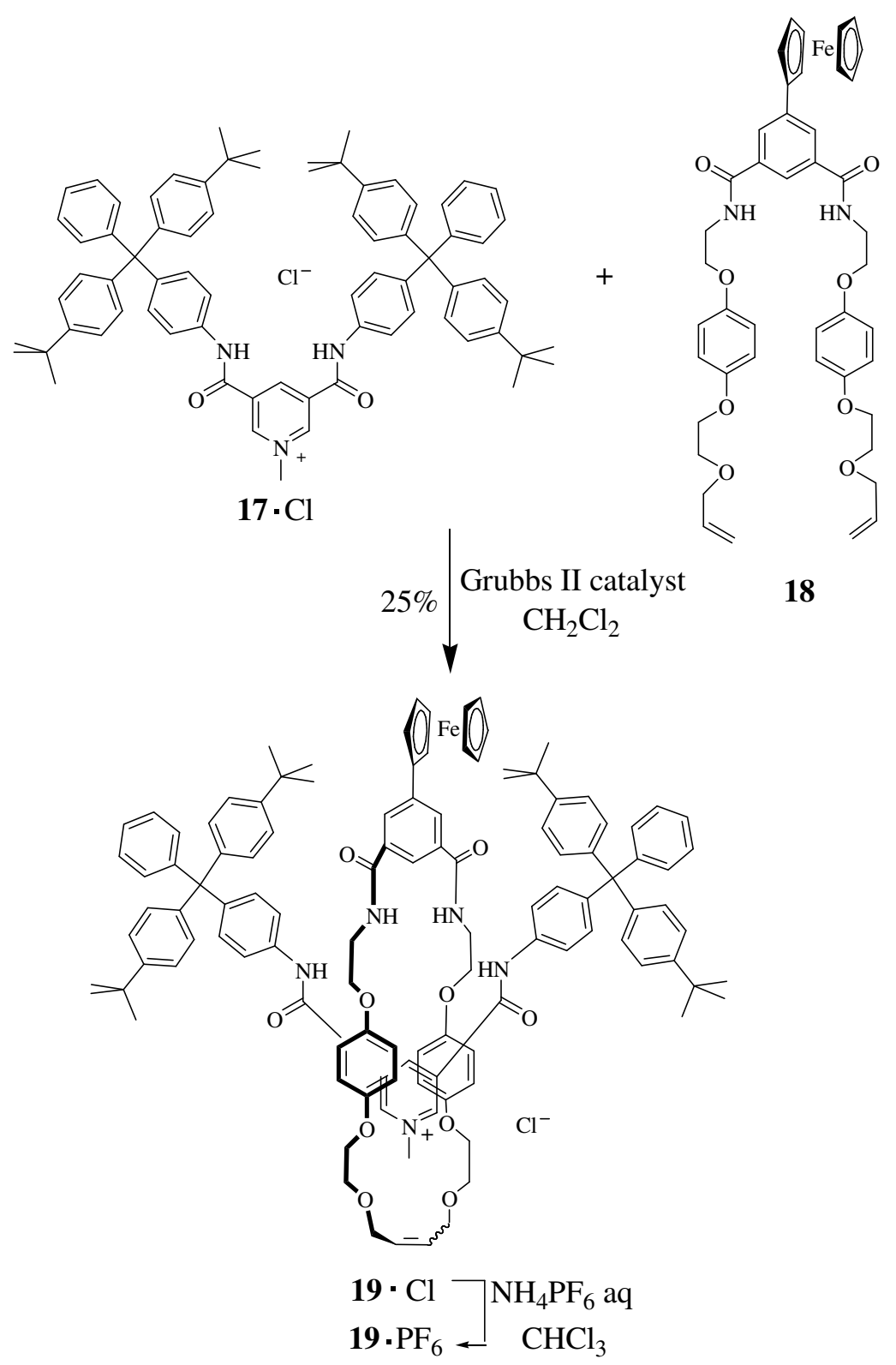

\section{Scheme 5}

\section{Example C}

Two porphyrin-functionalized rotaxanes $\mathbf{2 0} \cdot \mathrm{PF}_{6}$ and $\mathbf{2 1} \cdot \mathrm{PF}_{6}$ have been synthesized for investigation of their anion recognition abilities (Scheme 6). ${ }^{6}$ One should point out that porphyrins are interesting as potential reporter species due to their redox and optical properties. $^{69,70}$ 
For the synthesis of rotaxane $\mathbf{2 0} \cdot \mathrm{PF}_{6}$, in which two porphyrin units are appended to the thread, the compound $\mathbf{2 2} \cdot \mathrm{Cl}$ was treated with $\mathbf{2 3}$ as a bis-vinyl precursor of the ring in the presence of Grubbs second generation catalyst in $\mathrm{CH}_{2} \mathrm{Cl}_{2}$. The obtained rotaxane $20 \cdot \mathrm{Cl}$ upon ion exchange afforded rotaxane $\mathbf{2 0} \cdot \mathrm{PF}_{6}$. In both rotaxanes porphyrin units serve as large stoppers.

\section{Example C}

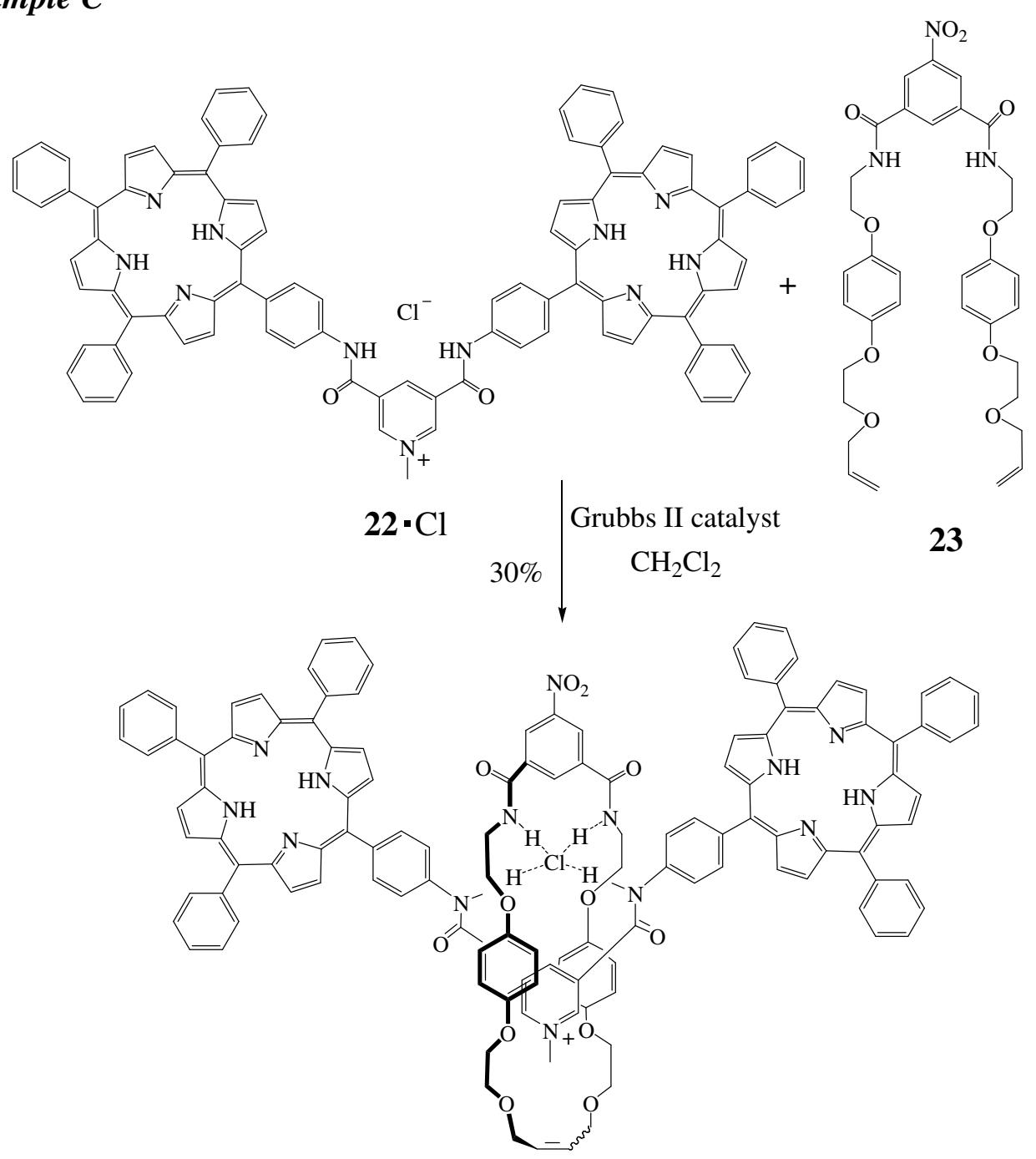

$20 \cdot \mathrm{Cl}$
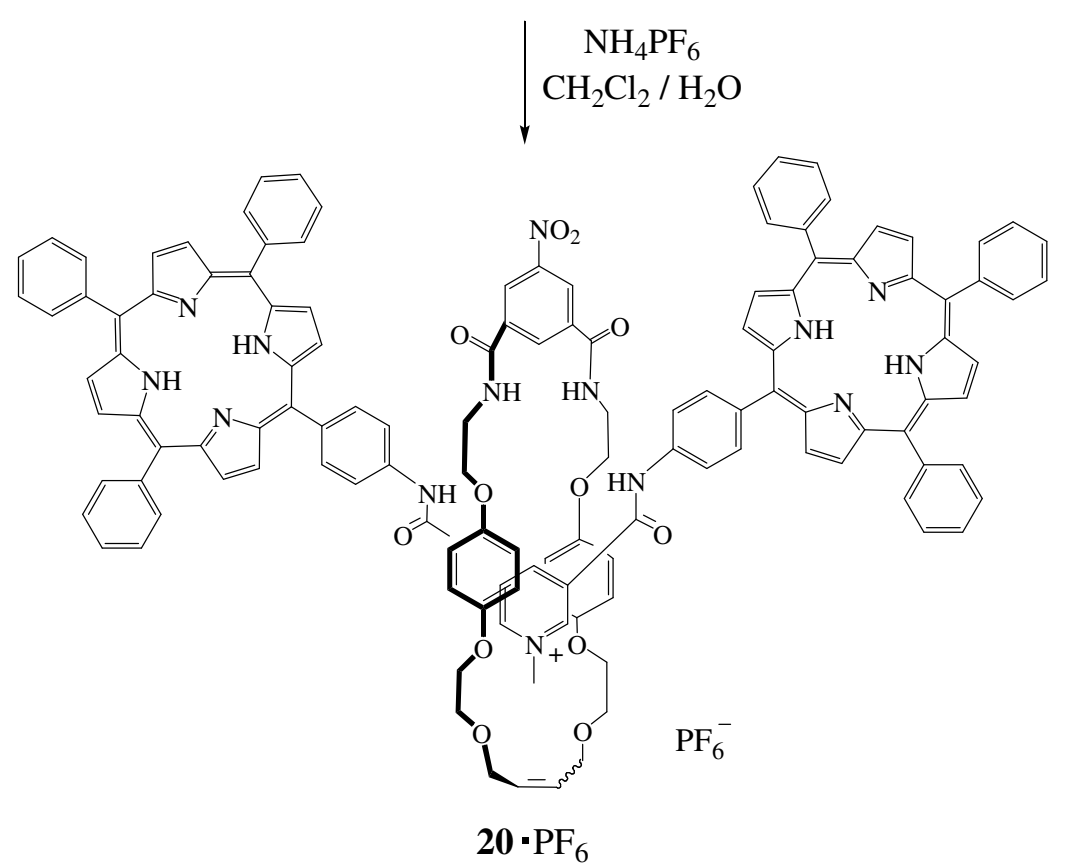

\section{Scheme 6}

Synthesis of rotaxane $\mathbf{2 1} \cdot \mathrm{PF}_{6}$, in which one porphyrin unit is appended to the ring begins with the treatment of porphyrin 24 with amine $\mathbf{2 5}$ leading to the ring precursor $\mathbf{2 6}$. The reaction of the thread $17 \cdot \mathrm{Cl}$ with 26 yielded rotaxane $\mathbf{2 1} \cdot \mathrm{Cl}$, converted by ion exchange into $21 \cdot \mathrm{PF}_{6}$ (Scheme 7). 
It was established that rotaxanes $\mathbf{2 0} \cdot \mathrm{PF}_{6}$ and $\mathbf{2 1} \cdot \mathrm{PF}_{6}$ show high binding selectivities to $\mathrm{Cl}^{-}$ over $\mathrm{Br}^{-}$and $\mathrm{NO}_{3}{ }^{-}$anions; moreover $21 \cdot \mathrm{PF}_{6}$ binds $\mathrm{Cl}^{-}$and $\mathrm{Br}^{-}$anions selectively over more basic $\mathrm{H}_{2} \mathrm{PO}_{4}{ }^{-}$and $\mathrm{AcO}^{-}$anions. Despite these properties the rotaxanes $\mathbf{2 0} \cdot \mathrm{PF}_{6}$ and $\mathbf{2 1} \cdot \mathrm{PF}_{6}$ are ineffective as optical anion sensors, but are capable for detection of $\mathrm{Cl}^{-}$anions electrochemically via cathodic shifts in the porphyrin $\mathrm{P} / \mathrm{P}^{+}$redox couples.

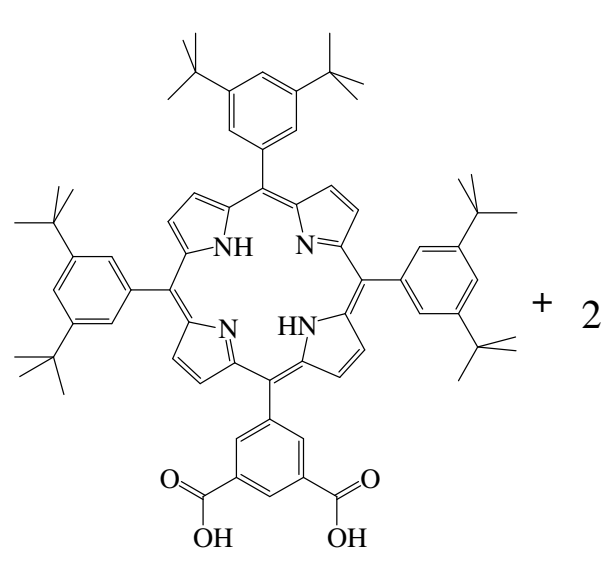

24

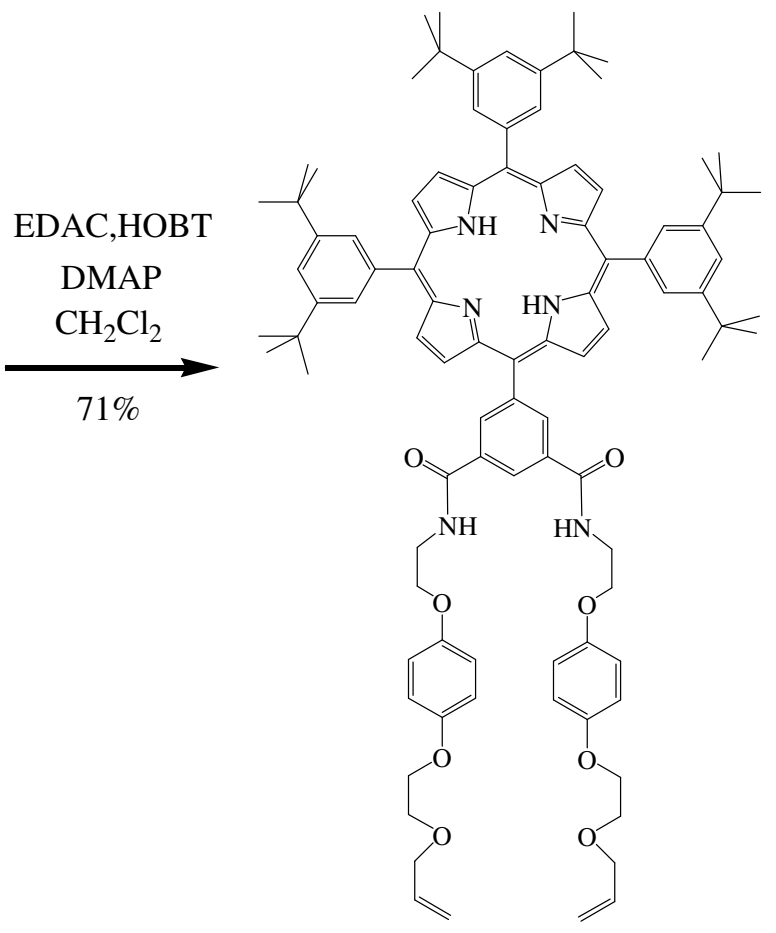

26

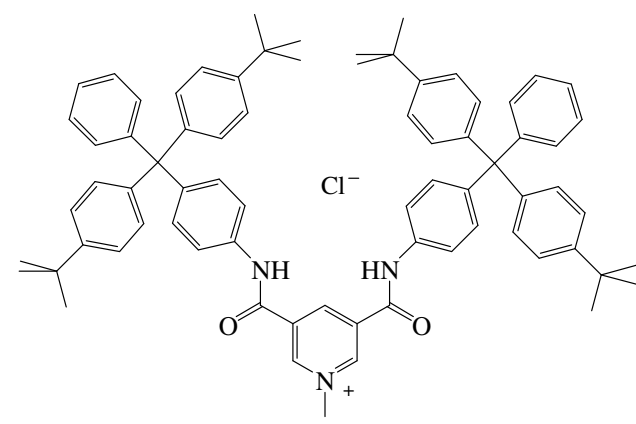

$17 \cdot \mathrm{Cl}$

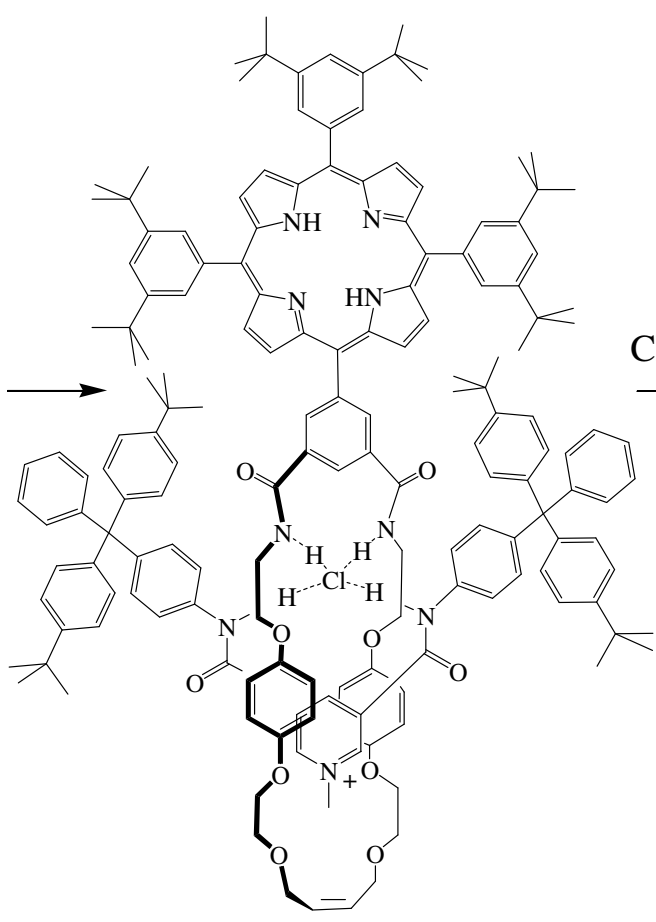

21. $\mathrm{Cl}$

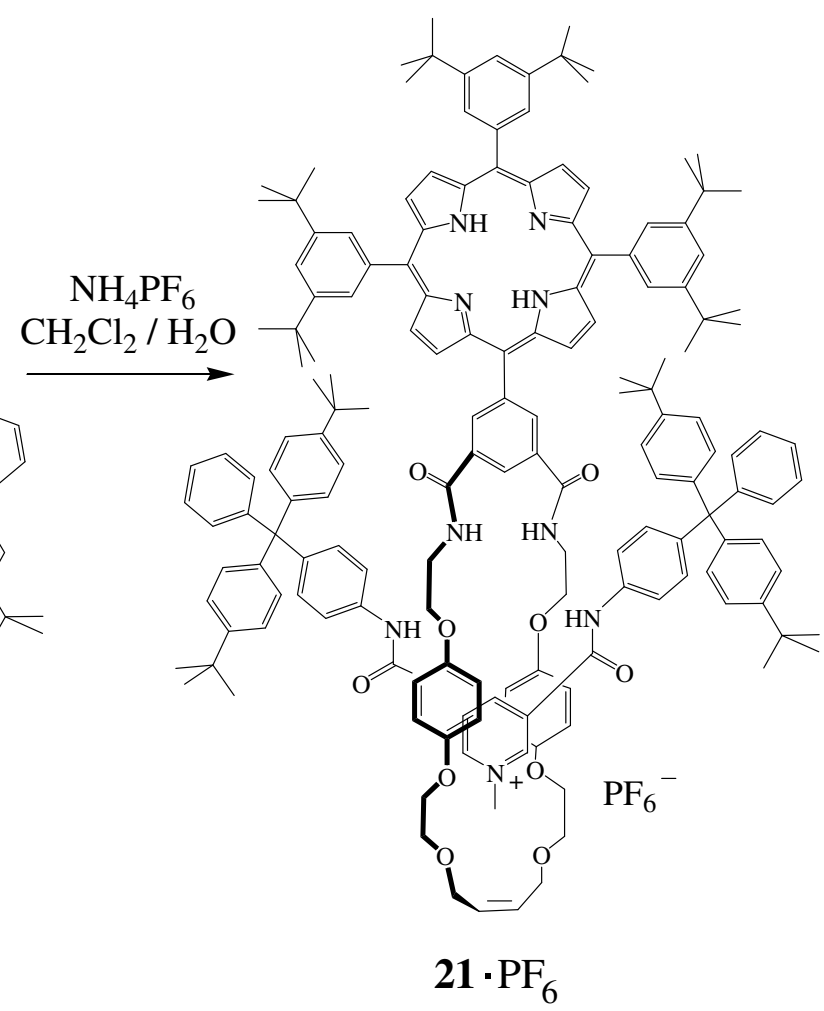

Scheme 7 


\subsection{Rotaxanes with rings built by condensation reactions}

In the synthesis of rotaxanes by chloride anion templation, an alternative method to that performed by RCM procedure, may be used. In this approach a diamine serving as a precursor of the ring undergoes cyclization by condensation reaction. Below two examples $A$ and $B$ of this method are presented.

\section{Example A}

The synthesis of [2] rotaxane composed of the thread $17 \cdot \mathrm{Cl}$ bearing pyridinium group and of the ring 29 containing crown ether unit was performed. The ring $\mathbf{2 9}$ was obtained by condensation of diamine 30 with pyridine 31 in $\mathrm{CH}_{2} \mathrm{Cl}_{2}$; it was found that the yield of this process increased when the reaction was carried out in the presence of pyridinium derivative $32 \cdot \mathrm{Cl}$. This observation indicates the existence of $\mathrm{Cl}^{-}$anion templation and a $\pi-\pi$ stacking between the positively charged electron-deficient pyridinium group of $32 \cdot \mathrm{Cl}$ and the electron rich hydroquinone motifs of $\mathbf{3 0}$, facilitating the cyclization (Scheme 8).

\section{Example A}

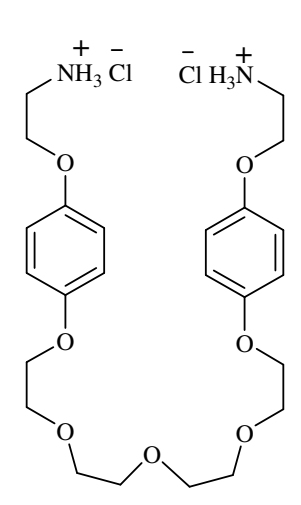

30

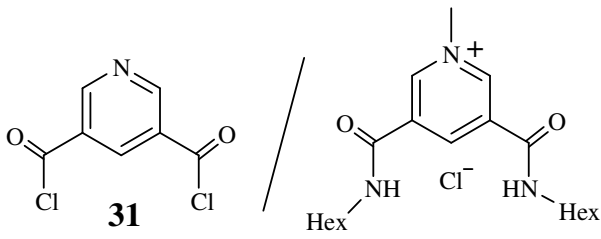

32- $\mathrm{Cl}$

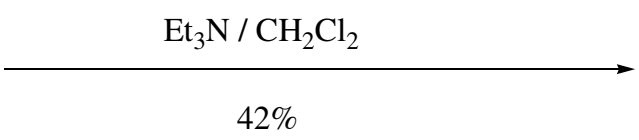

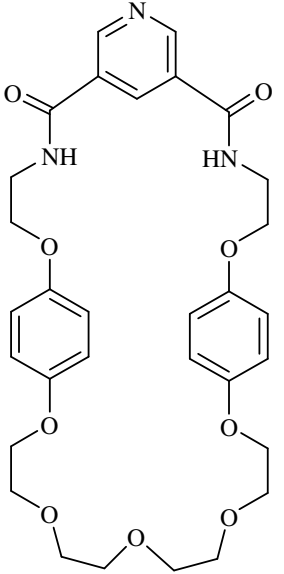

29

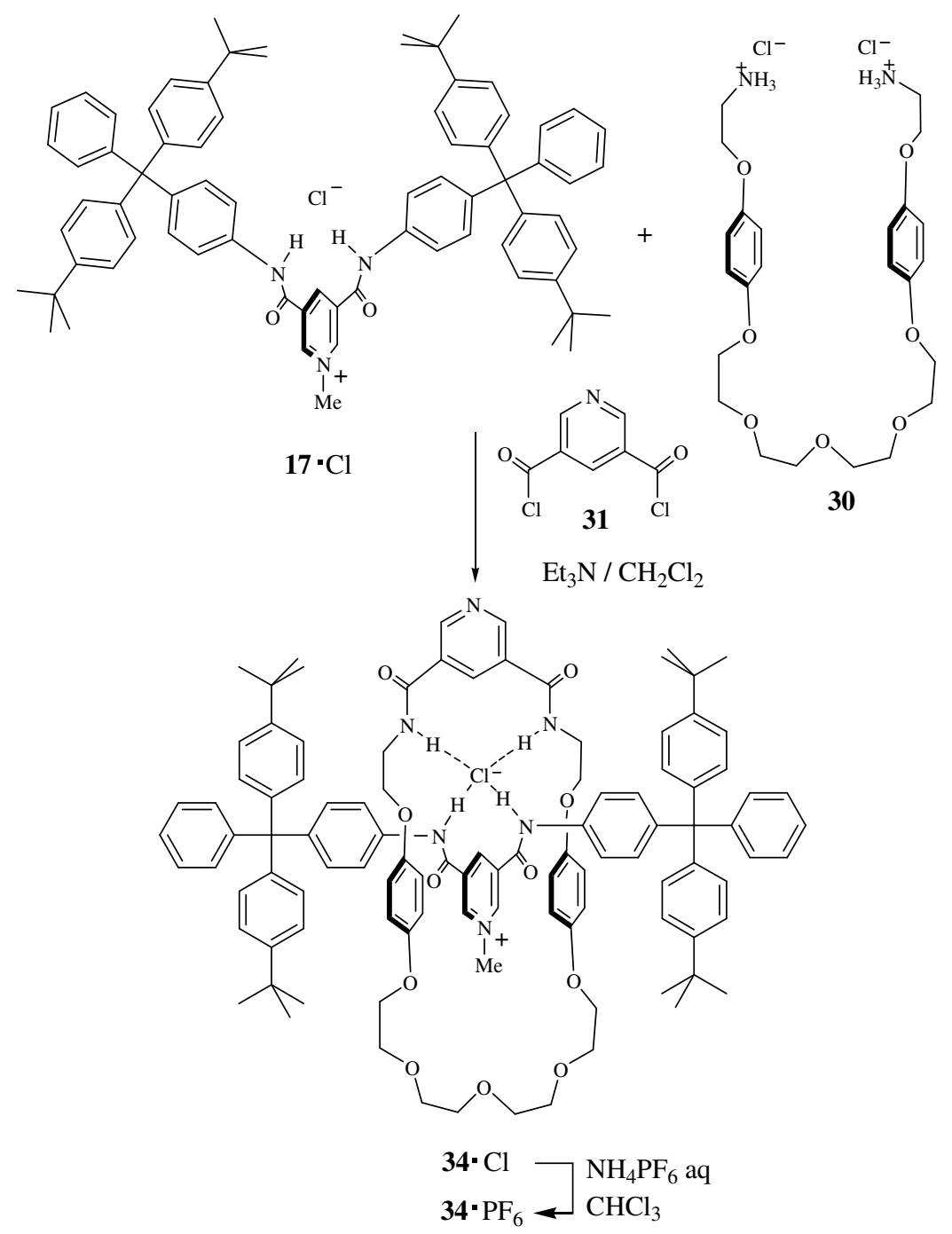

Scheme 8 
Having the above result in mind, it was supposed that the replacement of the pyridinium 32. $\mathrm{Cl}$ by pyridinium incorporated into the previously stoppered thread should afford a rotaxane. And indeed, the mixture of stoppered thread $\mathbf{1 7} \cdot \mathrm{Cl}$ and diamine $\mathbf{3 0}$ (in the form of hydrochloride) upon treatment with pyridine $\mathbf{3 1}$ yielded rotaxane $\mathbf{3 4} \cdot \mathrm{Cl}$ (Scheme 8$)^{71}$

In order to assess the ability of rotaxane 34 to bind anions, the removal of the $\mathrm{Cl}^{-}$anion from the interlocked cavity was made. For this purpose the chloride anion was exchanged for the noncoordinating hexafluorophosphate anion by repeated washing of $\mathbf{3 4} \cdot \mathrm{Cl}$ solution in chloroform with $\mathrm{NH}_{4} \mathrm{PF}_{6}$ aqueous solution to give $34 \cdot \mathrm{PF}_{6}$.

The anion binding properties of the rotaxane $\mathbf{3 4} \cdot \mathrm{PF}_{6}$ were studied by titration with TBA salts of $\mathrm{Cl}^{-}, \mathrm{Br}^{-}, \mathrm{H}_{2} \mathrm{PO}_{4}^{-}$and $\mathrm{AcO}^{-}$in $\mathrm{CDCl}_{3} / \mathrm{CD}_{3} \mathrm{OD}(1: 1)$ solution. The results indicate that the interlocked cavity of rotaxane $\mathbf{3 4} \cdot \mathrm{PF}_{6}$ is selective for $\mathrm{Cl}^{-}$above oxoanions; it has a size and shape complementary for $\mathrm{Cl}^{-}$, while the larger oxoanions cannot penetrate this cavity.

The described experiments show that the obtained interlocked systems are promising for application as anion sensors.

\section{Example B}

Using the above chloride anion templating method, syntheses of [2]rotaxanes able to recognize chloride anion in aqueous media were performed. Reactions of $\mathbf{1 7} \cdot \mathrm{Cl}$ with diamine $\mathbf{3 0}(\mathrm{n}=1)$ or $30(n=0)$ and appropriate bis(acid chloride) yielded two series of [2]rotaxanes, 33-35 and 36-38, respectively (Scheme 9). ${ }^{72}$

For example, the reaction of $\mathbf{1 7} \cdot \mathrm{Cl}$ with diamine $\mathbf{3 0}(\mathrm{n}=1)$ and 3,5bis(chlorocarbonyl)pyridine afforded rotaxane $\mathbf{3 4} \cdot \mathrm{Cl}$. This compound upon treatment with $\mathrm{NH}_{4} \mathrm{PF}_{6}$ was converted into $34 \cdot \mathrm{PF}_{6}$ which by methylation afforded the dicationic [2] rotaxane 39 $\cdot \mathrm{I}^{\mathrm{P}} \mathrm{F}_{6}$. The reaction of $\mathbf{3 4} \cdot \mathrm{Cl}$ upon ion exchange gave $\mathbf{3 4} \cdot \mathrm{PF}_{6}$ which was methylated and treated with $\mathrm{NH}_{4} \mathrm{PF}_{6}$ to give rotaxane $39 \cdot 2 \mathrm{PF}_{6}$ (not shown as a Scheme).

In a similar way $\mathbf{1 7} \cdot \mathrm{Cl}$ reacted with diamine $30(n=0)$ and 1,3 -benzenedisulfonyl chloride to give rotaxane $\mathbf{4 0} \cdot \mathrm{Cl}$, containing sulfonamide groups; it is the first rotaxane bearing sulfonamide groups.

Reaction of $\mathbf{1 7} \cdot \mathrm{X}\left(\mathrm{X}=\mathrm{Cl}, \mathrm{PF}_{6}\right)$ with diamine $30(\mathrm{n}=1)$ and the activated ester $\mathbf{A}$, (obtained in situ by treatment of isophthalic acid with $N$-hydroxysuccinimide in the presence of DCC) afforded rotaxanes $33 \cdot \mathrm{Cl}$ and $33 \cdot \mathrm{PF}_{6}$. It was observed that in the case of $\mathbf{1 7} \cdot \mathrm{Cl}$ used as a thread, the yield was higher than in the case of $\mathbf{1 7} \cdot \mathrm{PF}_{6}$; this fact indicates that chloride as a templating agent considerably enhances the rotaxane synthesis. ${ }^{72}$

For investigation of anion-binding properties of rotaxanes, the exchange of the chloride templating anion for the non-coordinating $\mathrm{PF}_{6}^{-}$was necessary. The anion-binding properties of rotaxanes $(\mathbf{3 3 - 3 8}) \cdot \mathrm{PF}_{6}$ were examined by ${ }^{1} \mathrm{HNMR}$ titration using TBA salts of $\mathrm{Cl}^{-}, \mathrm{H}_{2} \mathrm{PO}_{4}{ }^{-}$and $\mathrm{AcO}^{-}$anions in $\mathrm{CDCl}_{3} / \mathrm{CD}_{3} \mathrm{OD}(1: 1)$ solution. It was found that rotaxanes $(\mathbf{3 3 - 3 8}) \cdot \mathrm{PF}_{6}$ bind $\mathrm{Cl}^{-}$ anion very strongly $\left(K>10^{4} \mathrm{M}^{-1}\right)$.

Therefore similar anion-binding titrations were performed in the presence of $10 \%$ water; the calculation of association constants shows that the monocationic rotaxanes (33-38) $\cdot \mathrm{PF}_{6}$ bind chloride anion strongly even in this competitive aqueous solvent mixture, while the binding of oxoanions $\mathrm{H}_{2} \mathrm{PO}_{4}^{-}$and $\mathrm{OAc}^{-}$is only weak, despite the greater basicity of these anions. 


\section{Example B}

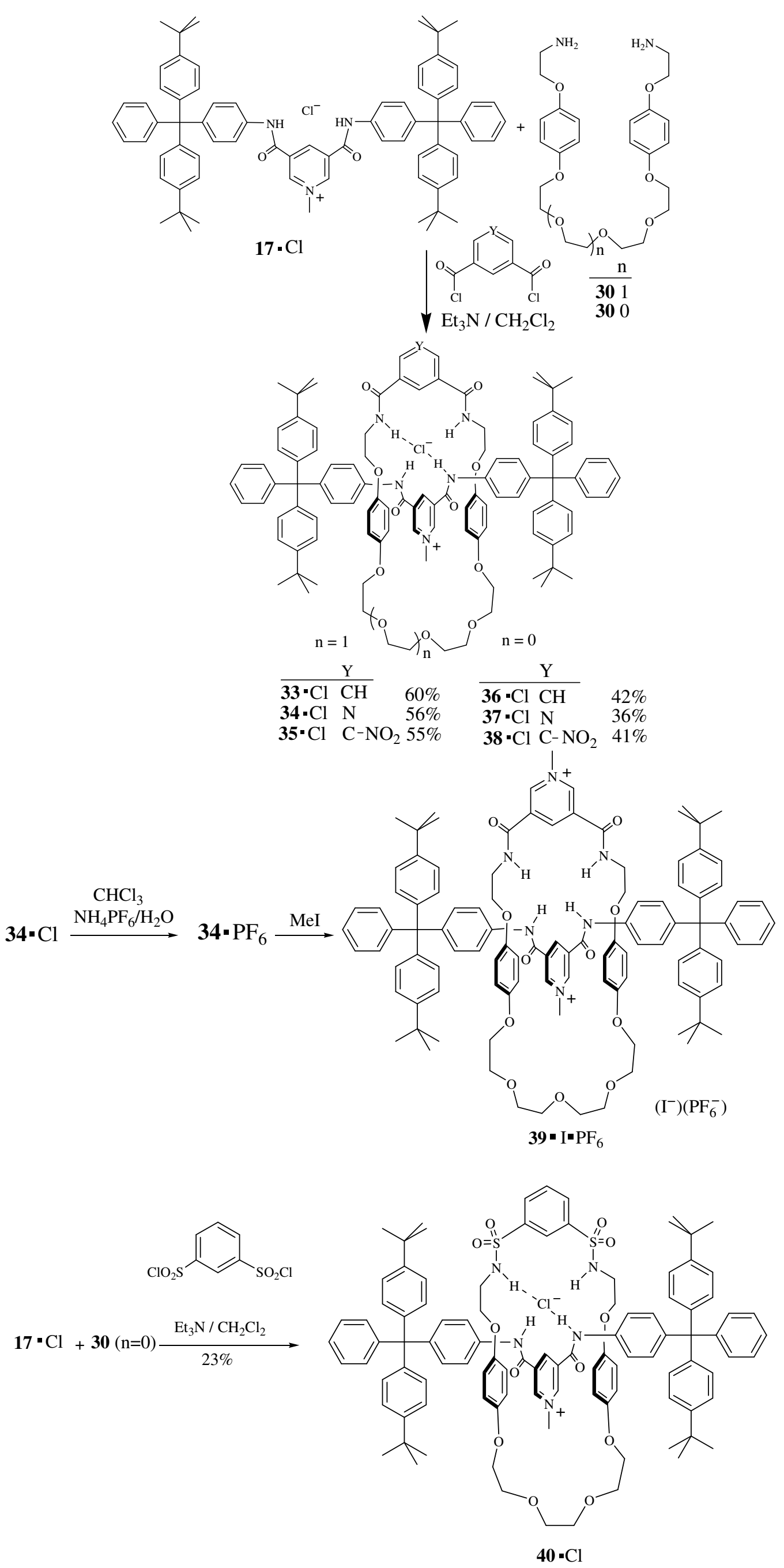




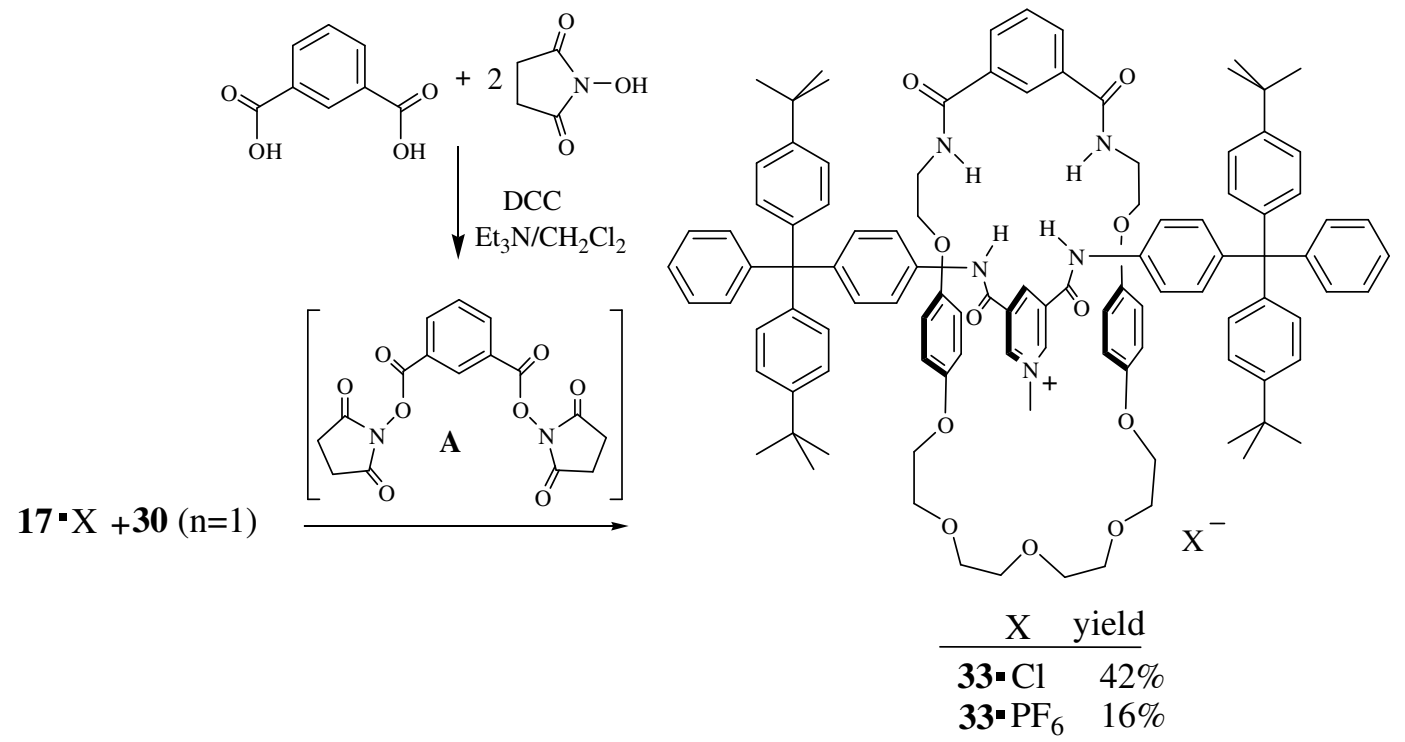

\section{Scheme 9}

It has been established that the $\mathrm{Cl}^{-}$binding of rotaxanes can be increased by the attachment of electron withdrawing substituents to the isophthalamide unit. This was confirmed by observation that rotaxanes containing the electron-withdrawing pyridine and nitroisophthalamide units, 34· $\mathrm{PF}_{6}$ and 35 $\cdot \mathrm{PF}_{6}$, respectively, show an enhanced affinity for $\mathrm{Cl}^{-}$. This fact is due to the increased acidity of amide protons, and as a result, their hydrogen-bonding ability to the anions.

It was found that the dicationic [2] rotaxane $39 \cdot \mathrm{I} \cdot \mathrm{PF}_{6}$ binds $\mathrm{Cl}^{-}$with $K_{\mathrm{a}}$ equal to $3000 \mathrm{M}^{-1}$ in the $10 \%$ water solvent system. This high $K_{\mathrm{a}}$ value results from the increased charge electrostatics, and, as a consequence, the higher acidity of the cavity protons of rotaxane. Therefore, the anionbinding investigation was made in a solvent system containing a higher, $35 \%$ percentage of water.

The orthogonal cavity disposition of the two 3,5-bisamide-substituted pyridinium motifs of the dicationic rotaxane $39 \cdot 2 \mathrm{PF}_{6}$ enhances the ability to selectively bind chloride even in $35 \%$ water, while no binding of oxoanions acetate or dihydrogen phosphate was observed, since they are too large to penetrate into the rotaxane pocket.

It is noteworthy that the strong binding of chloride anion by investigated rotaxanes is due to nearly total encapsulation of chloride in the isophthalamide cleft of the ring and due to the interaction with binding groups of the thread.

\subsection{Rotaxanes with previously prepared rings}

Two examples $A$ and $B$ for synthesis of rotaxanes, in which the rings were previously prepared, will be described here. Example $A$ concerns the synthesis of products by slippage, with the use of anion templation, and the subsequent conversion of these structures into rotaxanes. Example $B$ shows the procedure, which also may be presented here; it involves the use of the chloridepalladium coordination bond as a rotaxane-forming template.

\section{Example A}

Rotaxanes may be obtained using various methods, such as stoppering, ${ }^{73,74}$ or slipping, ${ }^{63,71}$ however, the slippage, i.e. slipping of the ring over one of the stoppers is not so widely investigated. Below the formation of rotaxanees by using slippage and anion templation is described.

Slippage usually involves heating the thread and ring in order to overcome the energy

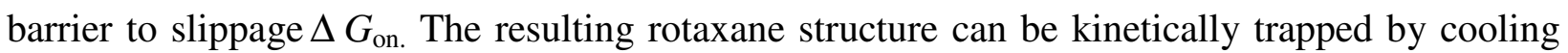
the equilibrated mixture to room temperature; in this process the barrier to slippage off ( $\Delta G_{\text {off }}$ ) cannot be overcome. ${ }^{75}$

The first examples of using slippage and anion templation to assemble rotaxanees, and investigate the role of the templating anion in the slippage process by kinetic methods, have been reported. ${ }^{76}$ In these experiments the ring $\mathbf{4 1}$ was obtained from $\mathbf{4 2}$ by Eglinton coupling of the terminal alkyne groups with copper(II) acetate. The ring $\mathbf{4 1}$ has an isophthalamide anion binding 
cavity and contains electron rich hydroquinone units for $\pi-\pi$ stacking interactions with the electron-deficient pyridinium unit of the thread (Scheme 10).

\section{Example A}
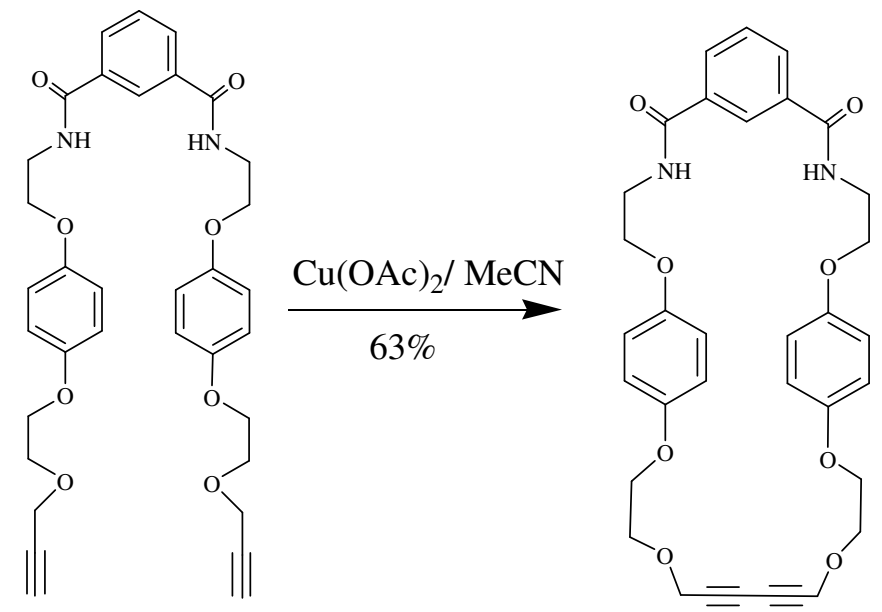

42

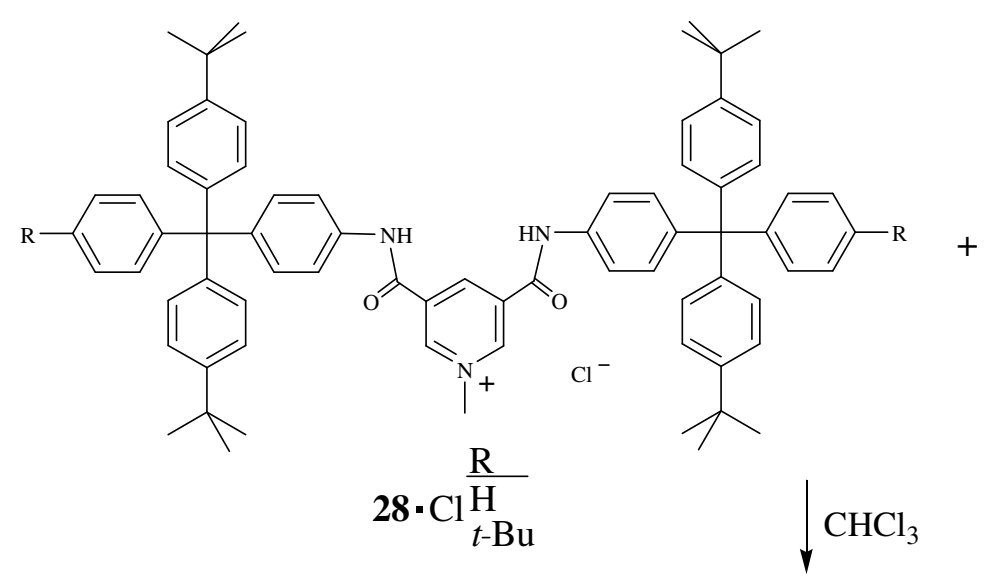

41

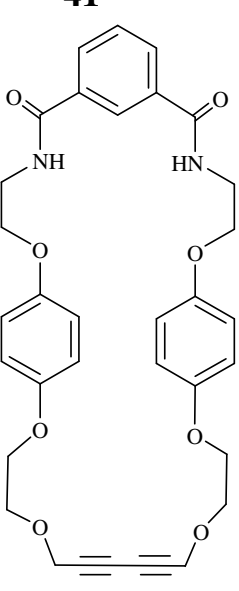

41

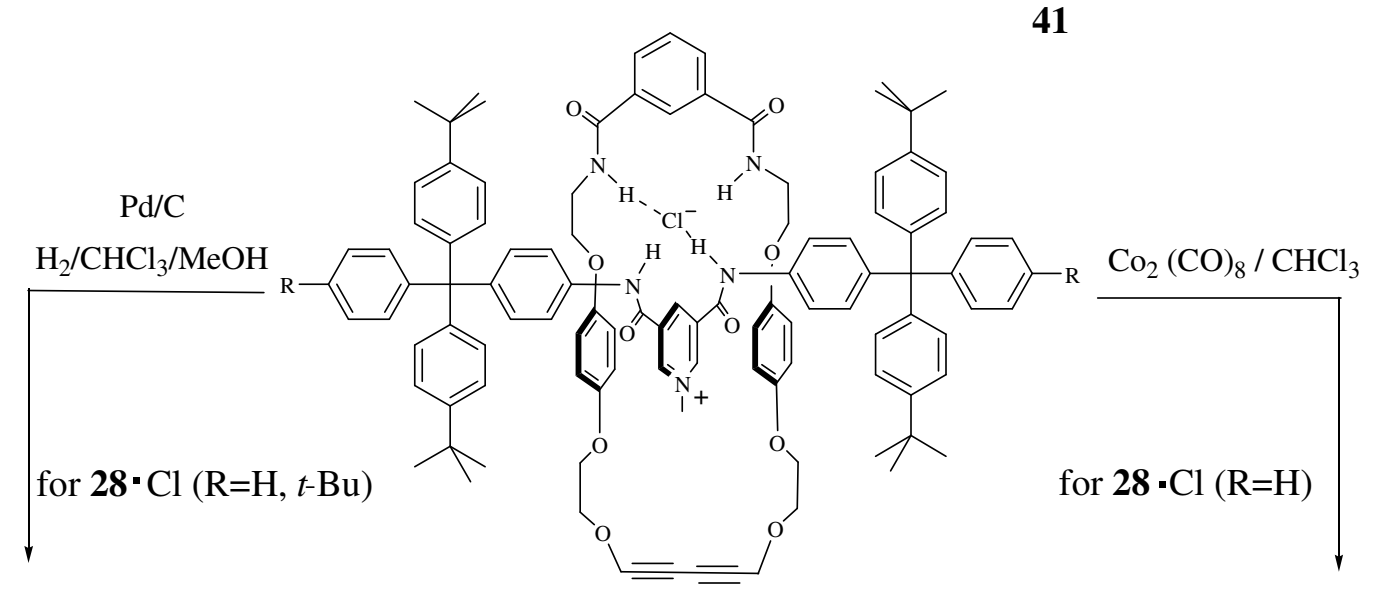

$\mathbf{4 3}_{\mathbf{b} \mathrm{a}}^{\mathrm{R}} \frac{\mathrm{R}}{\mathrm{H} \text { Bu }}$

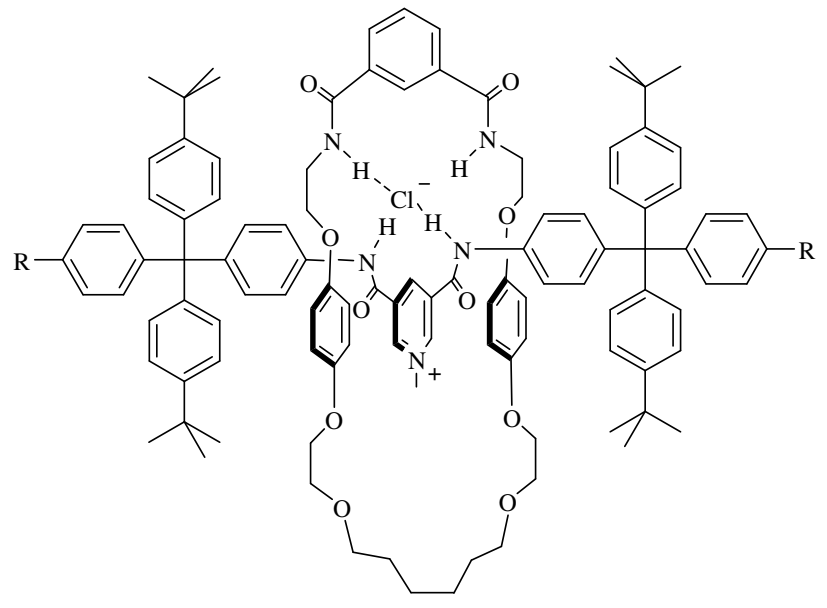

44. $\mathrm{Cl} \underset{t-\mathrm{Bu}}{\frac{\mathrm{R}}{\mathrm{H}}}$

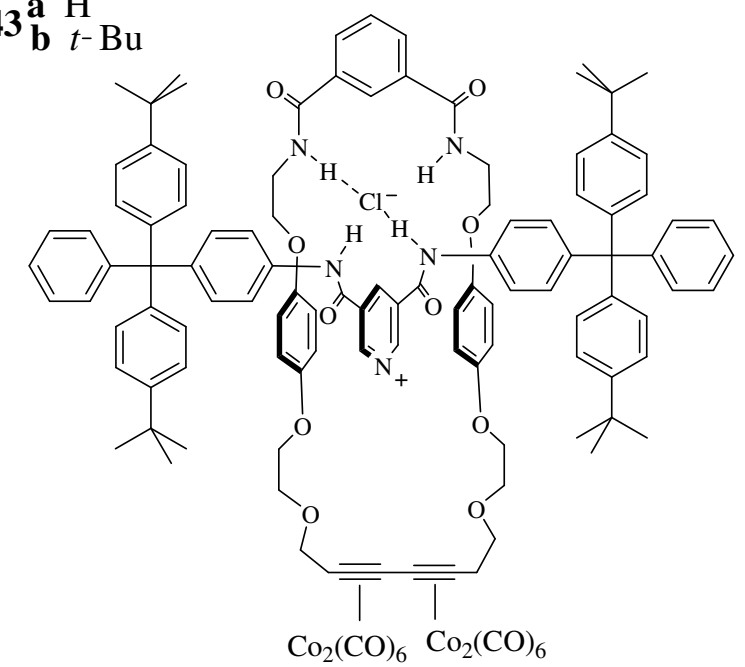

45. $\mathrm{Cl}$

\section{Scheme 10}


It was found that the terphenyl stoppered threads $28 \cdot \mathrm{Cl}(\mathrm{R}=\mathrm{H}, t$-Bu) form by equilibration with $\mathbf{4 1}$ in the presence of an anion template (here chloride), via slippage, the structures $\mathbf{4 3 a}, \mathbf{b}$, which may be converted into rotaxanes by using two strategies: hydrogenation or complexation with cobalt carbonyl.

- Hydrogenation of the diyne group with the use of palladium on carbon under a hydrogen atmosphere in the presence of methanol affords rotaxanes $44 \cdot \mathrm{Cl}(\mathrm{R}=\mathrm{H})$ and $\mathbf{4 4 \cdot} \mathrm{Cl}$ $(\mathrm{R}=t-\mathrm{Bu})$.

- Complexation of the diyne group with cobalt carbonyl yields the rotaxane $45 \cdot \mathrm{Cl}$.

\section{Example B}

In the following experiment the synthesis of rotaxane is templated by formation of the anionpalladium coordination bond. It was also observed that chloride anion may induce shuttling of a rotaxane. One should point out that the use of anions to induce shuttling in rotaxanes ${ }^{77}$ has not been so widely studied as the use of other stimuli; especially the ability of halides to form strong coordination bonds with transition metals up to now is rather seldom exploited. Below also the chloride-switchable molecular shuttle is described.

It was found that the displacement of the acetonitrile ligand from the complex $\mathbf{4 6}$ by the chloride ion of benzylpyridinium chloride $47 \cdot \mathrm{Cl}$ resulted in the encapsulation of the cationic $\mathbf{4 7}^{+}$ by the anionic PdCl-coordinated ring to give pseudorotaxane $48 .^{78}$ It is noteworthy that the chloride anion plays a crucial role in threading; this observation was confirmed by the fact that the use of $\mathbf{4 7} \cdot \mathrm{PF}_{6}$ did not result in threading. The above described result is promising for design of anion selective triggers.

For investigation of chloride-switchable molecular shuttle, first the click reaction of $49 \cdot \mathrm{Cl}$ having the terminal alkynyl group with azide $\mathbf{5 0}$ and with complex 46 was made. In the formed rotaxane $\mathbf{5 1}$ the ring encircles the pyridinium station, and $\mathrm{Cl}^{-}$anion is a coordinating ligand.

In order to obtain a molecular shuttle, rotaxane $\mathbf{5 1}$ was treated with $\mathrm{AgPF}_{6}$; this reaction results in the precipitation of $\mathrm{AgCl}$ and shift of the ring to the second station, i.e. triazole unit; in this process the rotaxane $\mathbf{5 2}$ is formed. The triazole unit is now a coordination site, and the coordinating ligand $\mathrm{Cl}^{-}$is replaced by the noncoordinating $\mathrm{PF}_{6}{ }^{-}$counterion. The addition of $\mathrm{Bu}_{4} \mathrm{NCl}$ to 52 restores the starting rotaxane $\mathbf{5 1}$ (Scheme 11).

One may conclude that the reported formation of the anion-palladium coordination bond may be used as an efficient rotaxane-forming template as well as the basis for a chloride -switchable molecular shuttle and is of interest for construction of sensors and molecular machines.

\section{Example $B$}
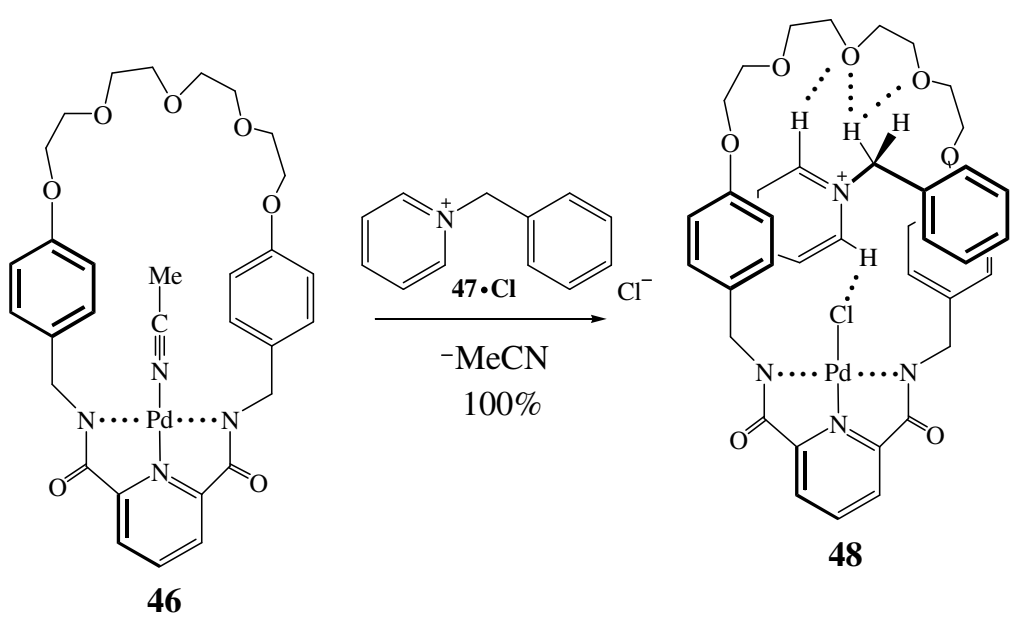


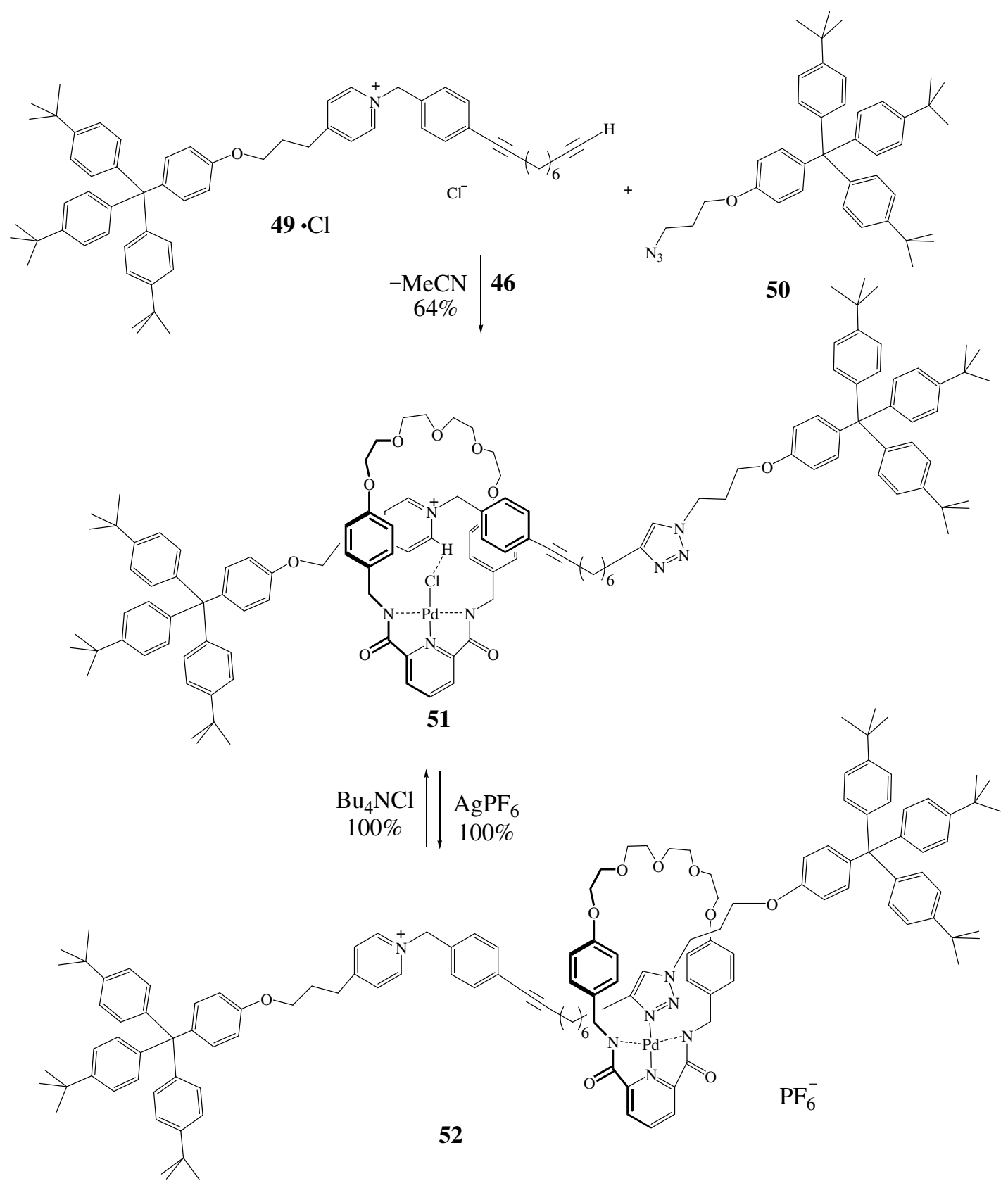

\section{Scheme 11}

\section{Rotaxane-based molecular machines}

Construction of molecular machines is a great challenge on the scientific field; a special attention is paid today to rotaxane-based molecular machines, ${ }^{79}$ interesting in the area of novel materials $^{80,81}$ and medicine. ${ }^{82,83}$

Rotaxane $\mathbf{5 3} \cdot 2 \mathrm{PF}_{6}$, acting as molecular shuttle was synthesized in one-pot reaction from pyridine derivative $\mathbf{5 4}$, dipyridyl dibromide 55 and crown ether $\mathbf{Z}{ }^{84}$ In rotaxane $\mathbf{5 3} \cdot 2 \mathrm{PF}_{6}$ the ring can reside either on the central 2,2'- bipyridine station $\mathbf{C}$ or on one of the two terminal monopyridinium stations $\mathbf{A}$ or $\mathbf{B}$ (here the ring residing on $\mathbf{A}$ is shown) and can shuttle between $\mathbf{A}$ and $\mathbf{B}$ by addition of simple reagents such as acid/base or metal ion/metal ion complexing ligand pairs (Scheme 12).

The X-ray crystallographic analysis of $\mathbf{5 3} \cdot 2 \mathrm{PF}_{6}$ shows that the ring encircles one of the pyridinium units, $\mathbf{A}$ or $\mathbf{B}$, affording rotaxanes $\mathbf{K}$ or $\mathbf{M}$, respectively, which undergo a shuttling. It was observed that upon protonation of $\mathbf{K}$ the ring encircles stronger the doubly protonated 2,2'bipyridinium ion $\mathbf{C}$ than monopyridinium ions $\mathbf{A}$ or $\mathbf{B}$ in $\mathrm{CD}_{3} \mathrm{NO}_{2}$, therefore upon addition of TFA to $\mathbf{K}$, the ring moves from pyridinium ion $\mathbf{A}$ (shown here) or $\mathbf{B}$ to 2,2'-bipyridinium unit $\mathbf{C}$ to give $\mathbf{L}$; this process is reversible, the treatment of $\mathbf{L}$ with $\mathrm{Et}_{3} \mathrm{~N}$ restores $\mathbf{K}$.

Since the ring is small, the coordination of a suitable metal ion or its associated ligands to the group $\mathbf{C}$ can stop the shuttling $\mathbf{K} / \mathbf{M}$ and force the ring to reside on $\mathbf{A}$ or $\mathbf{B}$. For this purpose $\mathrm{Zn}(\mathrm{OAc})_{2}$ was added to the solution of $\mathbf{5 3} \cdot 2 \mathrm{PF}_{6}$ in $\mathrm{CD}_{3} \mathrm{NO}_{2}$; as a result the compound $\mathbf{N}$ was 
formed, in which the ring encircles one of the pyridinium stations (here $\mathbf{B}$ ). The coordinated $\mathrm{Zn}^{2+}$ ion can be removed from the station $\mathbf{C}$ by addition of tetrapyridineethylenediamine (TPEN) which strongly binds $\mathrm{Zn}^{2+}$. As a result, the compound $\mathbf{M}$ is recovered. In this way the shuttling of the ring between two monopyridinium units $\mathbf{A}$ and $\mathbf{B}$ was regenerated, i.e. the compounds $\mathbf{K}$ and M were restored. ${ }^{84}$

The above system mimics the behavior of a molecular machine in which the molecular motion can be stopped and restarted, and due to presence of three discrete states the design of molecular switches, sensors or logic gates is possible.

Other molecular machines were selected from investigations on mannosylrotaxanes; below three examples $A-C$ are presented.
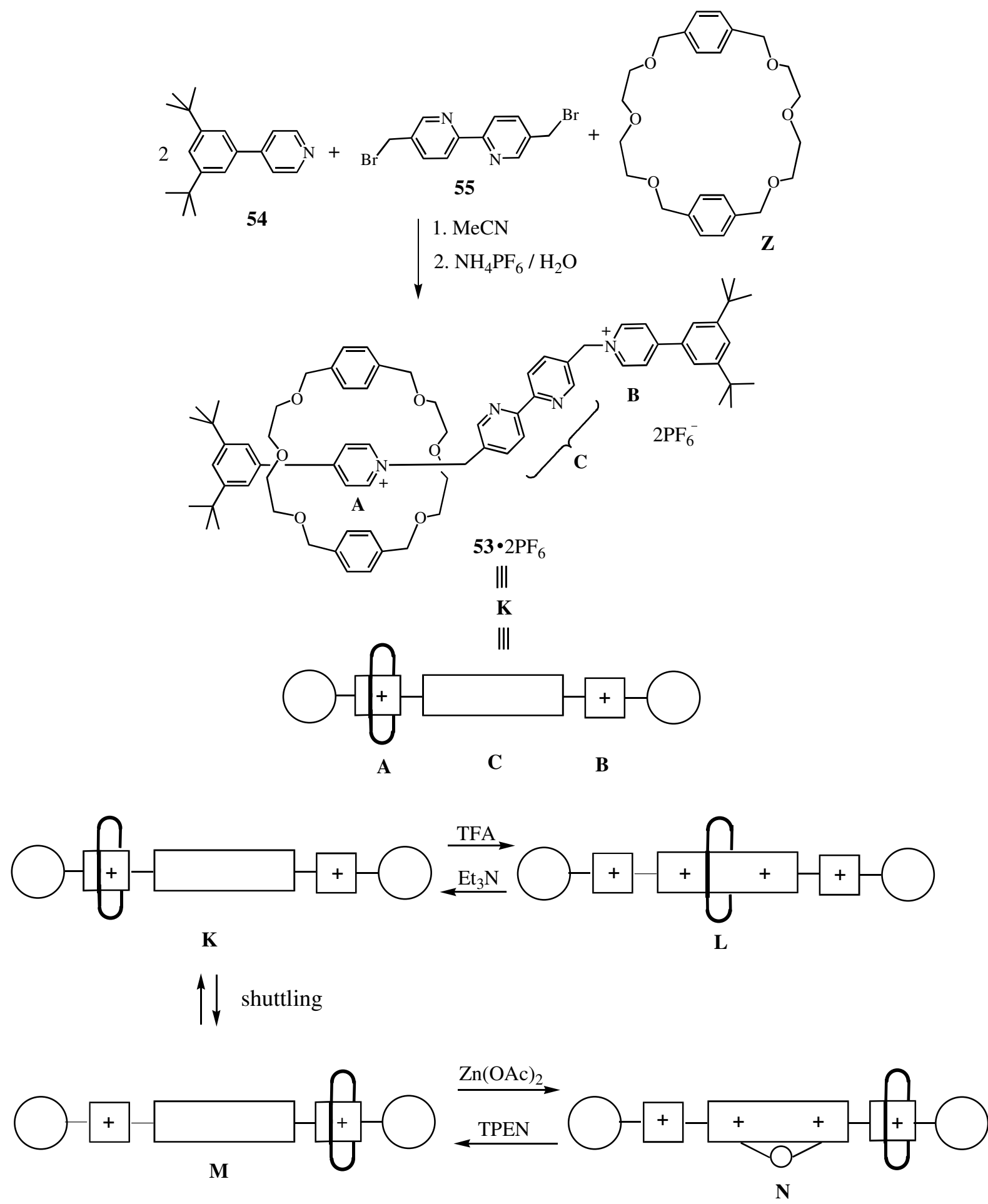<smiles>CC(C)N=[N+]=NCc1ccccn1</smiles>

$O=\mathrm{Zn}^{2+}$

Scheme 12 


\section{Example $A$}

In the study of glycorotaxanes as corresponding molecular muscles ${ }^{85}$ and machines, ${ }^{86}$ the two large amplitude mannosyl[2]rotaxane molecular machines $\mathbf{5 6 a , b}$ have been synthesized from mannosylpyridinium azide $\mathbf{5 7 a}, \mathbf{b}$ and the alkyne $\mathbf{5 8}$ in the presence of dibenzo[24]crown- 8 (DB24C8) by using click chemistry. ${ }^{87}$ Their thread bears two stations: an anilinium and a monoor disubstituted pyridinium amide, and the ring is DB24C8 (Scheme 13).

\section{Example A}
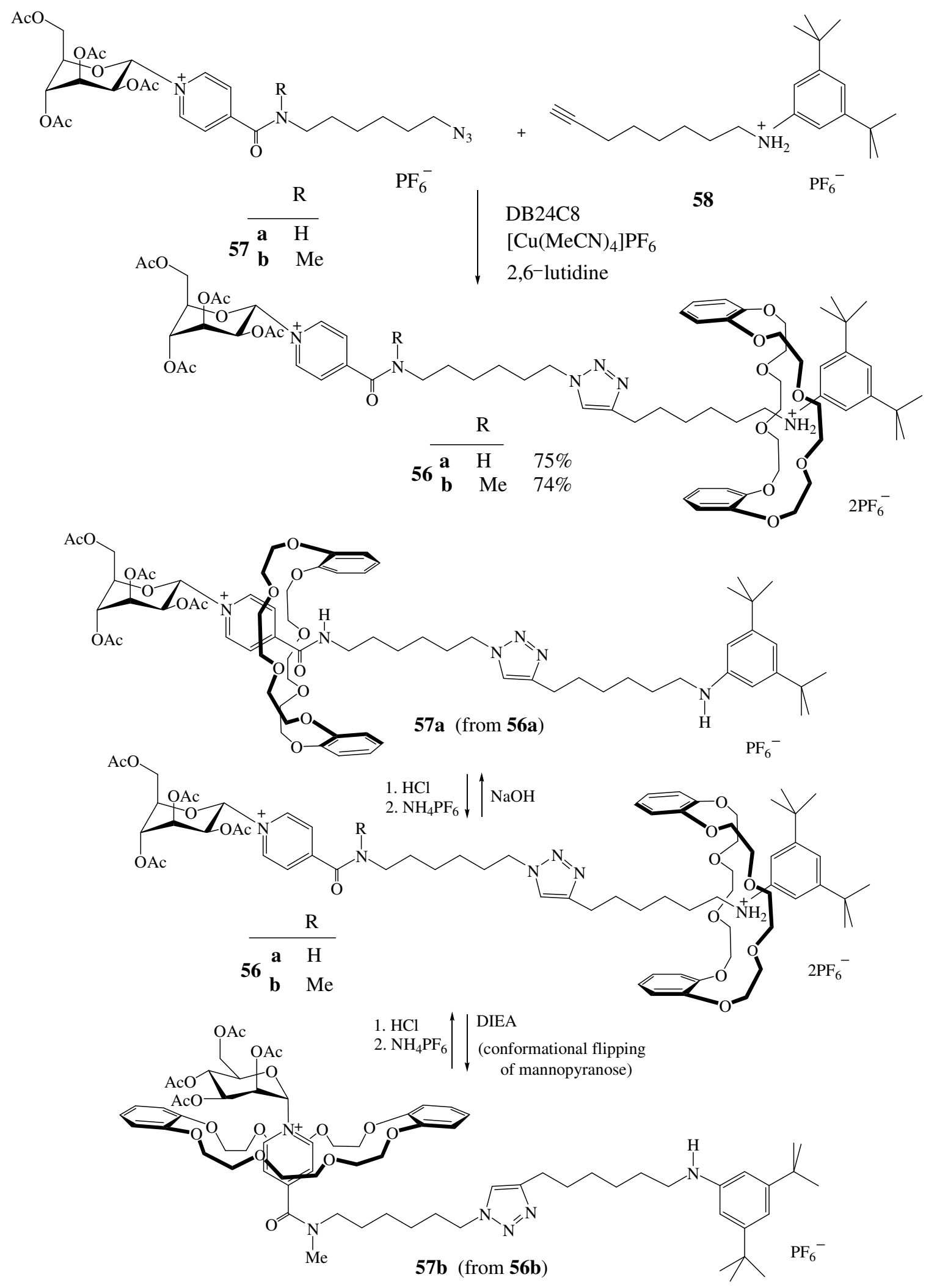

\section{Scheme 13}

Anilinium is much better station than the pyridinium amide. Upon deprotonation of the anilinium by diisopropylethylamine (DIEA) the ring shuttles toward the pyridinium amide station. It was found that the resulting interaction of the ring with pyridinium amide depends on its mono- or disubstitution. 
- In the case of monosubstituted pyridinium amide in 56a, the ring encircles the NH group to give rotaxane 57a; the oxygen atoms of the ring form hydrogen bonds with the amide hydrogen $\mathrm{NH}$ and with the neighboring $\mathrm{H}_{\beta}$ atoms of the pyridinium unit.

- In the case of the disubstituted pyridinium amide in $\mathbf{5 6 \mathbf { b }}$, however, the ring is localized around the positive charge of pyridinium unit to give rotaxane $\mathbf{5 7 \mathbf { b }}$; the ring forms hydrogen bonds with $\mathrm{H}_{\alpha}$ atoms of pyridinium unit which are situated near the cationic nitrogen atom, and interacts by ion-dipole contacts with the cationic charge. This behavior results in the conformational flipping of the mannopyranose from ${ }^{1} \mathrm{C}_{4}$ to ${ }^{4} \mathrm{C}_{1}$; in $\mathbf{5 6 a}$ and $\mathbf{5 7 a}$ the chair conformation of mannopyranose is ${ }^{1} \mathrm{C}_{4}$ while in $\mathbf{5 7 b}$ it is ${ }^{4} \mathrm{C}_{1} \cdot{ }^{87}$

The above observations show that rotaxanes $\mathbf{5 6 b}$ and $\mathbf{5 7 b}$ are examples of molecular machines able to cause conformational changes of a glucidic stopper by the ring shuttling which results from the $\mathrm{pH}$ variation.

It should be pointed out that this domino effect from one end of the molecule to the other, i.e. deprotonation of the anilinium station/translation of the ring/conformational isomerization of the mannosyl stopper is a molecular mimic of behavior of an allosteric biomacromolecule.

\section{Example B}

The three-station glycorotaxanes $\mathbf{5 8 a , b}$ acting as molecular machines have been synthesized from rotaxanes $\mathbf{5 6} \mathbf{6}, \mathbf{b}$. In this process rotaxanes $\mathbf{5 6} \mathbf{a}, \mathbf{b}$ upon methylation of the triazole unit yield rotaxanes 58a,b bearing three stations, i.e. anilinium, mono- or disubstituted pyridinium amide and $N$-methyltriazolium (Scheme 14).

The affinity of the ring for the stations at room temperature decreases in the order: anilinium $>$ monosubstituted pyridinium amide $\approx N$-methyltriazolium $>$ disubstituted pyridinium amide $>$ aniline. The exchange between these three stations is fast on the NMR time-scale for temperatures $298-193 \mathrm{~K}^{88}$

Anilinium is the best station for the ring, therefore at low $\mathrm{pH}$ the ring resides exclusively at the anilinium station. Deprotonation of $\mathbf{5 8 a , b}$ by diisopropylethylamine (DIEA) results in the displacement of the ring affording $\mathbf{5 9} \mathbf{a}$ and $\mathbf{5 9} \mathbf{b}$, respectively.

Rotaxanes $\mathbf{5 8 a / 5 9 a}$ and $\mathbf{5 8 b / 5 9 b}$ act as molecular machines by acid-base reaction as described below.

\section{Action of rotaxanes $\mathbf{5 8 a / 5 9}$ a as molecular machines}

In the case of monosubstituted pyridinium amide in 58a the ring resides at the best station, i.e. anilinium, but after deprotonation of anilinium, in 59a the shuttling occurs as in a degenerate molecular machine; the ring oscillates between $N$-methyltriazolium and monosubstituted pyridinium amide. The exchange between two translational isomers $59 \mathbf{a}_{1}$ and $\mathbf{5 9} \mathbf{a}_{2}$ is fast on the NMR timescale.

At room temperature a slight preference for the pyridinium amide is observed. Lowering the temperature increases $\Delta G$, and as a result the ring resides more and more at pyridinium amide. Around $223 \mathrm{~K}$ the oscillation between two stations stops, and the ring spends most of its time at pyridinium amide, like in a bistable molecular machine. Increasing the temperature restores the oscillation movement, while the reprotonation of the aniline station stops the oscillation, and as a result the ring resides exclusively at the anilinium station.

It is noteworthy that in 59a the ring acts as a molecular brake of rotation of the covalent bond between the pyridinium and the amide carbonyl group. When the ring is located between pyridinium and amide, it interacts by hydrogen bonding with both the pyridinium hydrogen atoms and with the amide $\mathrm{NH}$ at the same time. The ring is anchored at the two H-bonding sites and in this way surrounds the pyridinium-amide linkage; as a result the ring disturbs rotation of this linkage. 


\section{Example B}
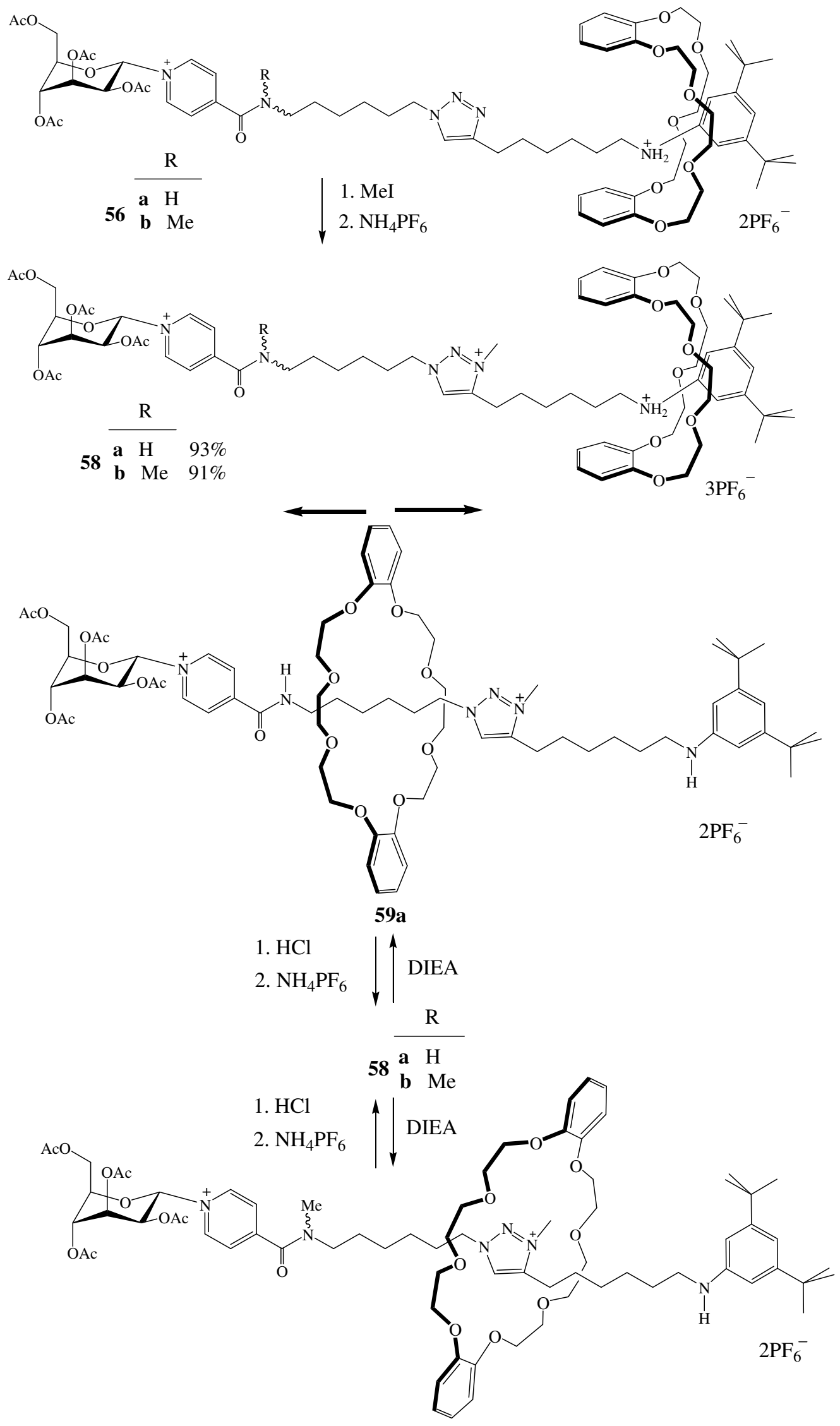

59b 


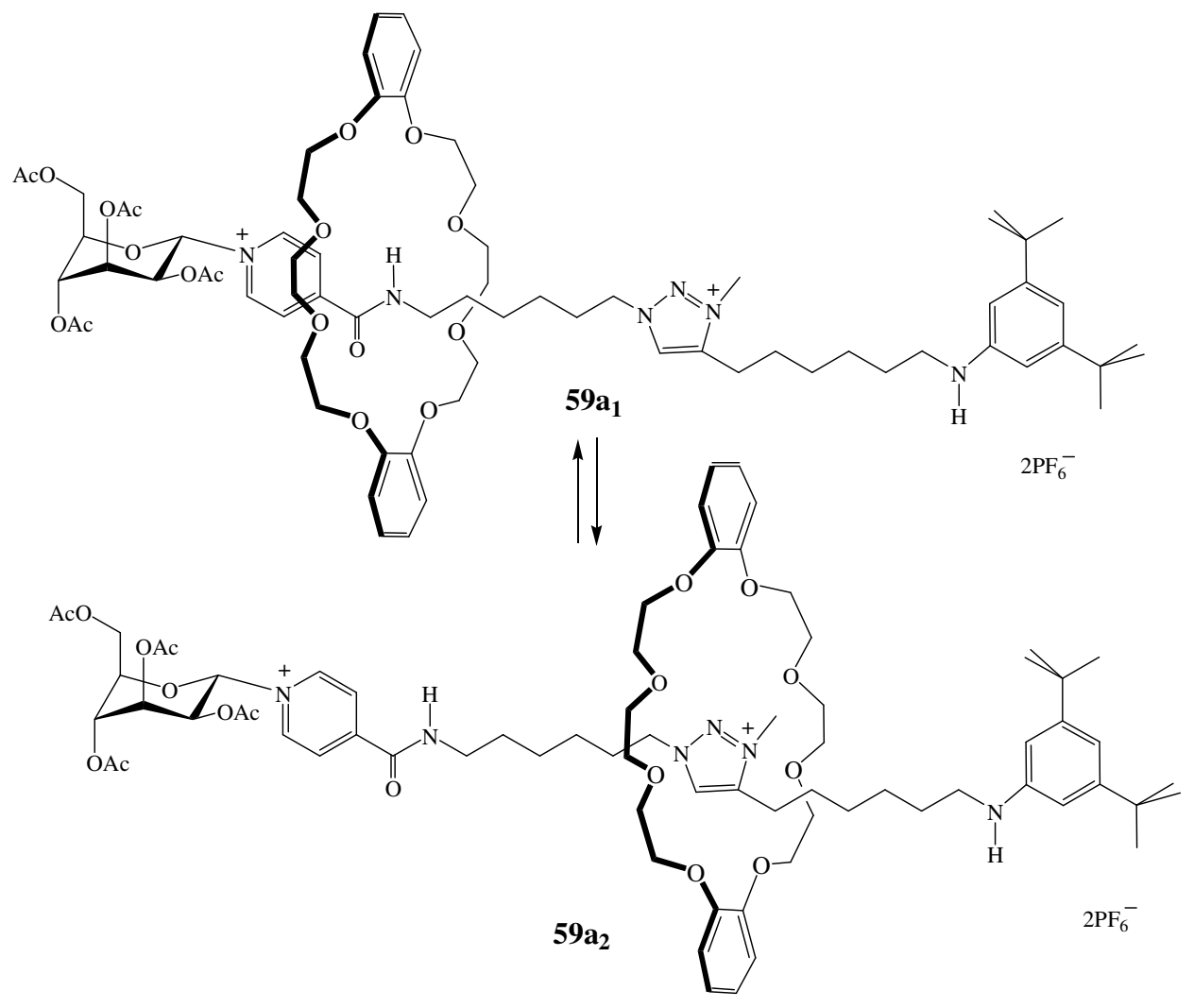

\section{Scheme 14}

\section{Action of rotaxanes $\mathbf{5 8 b / 5 9 b}$ as molecular machines}

In the case of disubstituted pyridinium amide in $\mathbf{5 8 b}$, the ring resides at the best station, i.e. anilinium, but after deprotonation of anilinium, in 59b the ring moves to $N$-methyltriazolium station (which is a better station for the ring than the disubstituted pyridinium amide) and resides at the $\mathrm{N}$-methyltriazolium station. The molecular machine created in this way behaves as a $\mathrm{pH}-$ sensitive bistable [2] rotaxane in which the ring shuttles between the anilinium and $N$ methyltriazolium stations and is located at either anilinium or $N$-methyltriazolium station, depending on $\mathrm{pH}^{88}$

\section{Example C}

To rotaxane-based molecular machines belong [c2] daisy chains acting as molecular muscles. ${ }^{89}$ It is known that [c2]daisy chains containing two stations may adopt contracted or extended coconformation, giving rise to their action as muscles. ${ }^{90}$ The described below work is an interesting example of molecular machine built from [c2]daisy chains containing two and three stations.

Four mannosyl[c2]daisy chains containing two and three stations have been synthesized and their shuttling behavior was studied. These compounds act as molecular machines triggered by deprotonation/carbamoylation, temperature and solvent polarity.

The synthesis begins with the click reaction of mannosyl pyridinium azide 57a,b with alkyne 60 leading to rotaxanes 61a,b containing two stations: ammonium and mono- or disubstituted pyridinium amide. These compounds upon methylation of the triazole unit afford rotaxanes 62a,b bearing three stations; i.e. ammonium, substituted pyridinium amide and $N$ methyltriazolium. ${ }^{91}$ It was found that in the case of protonated ammonium stations the daisy chains adopt the extended co-conformation (Scheme 15).

The deprotonation/carbamoylation process of $\mathbf{6 1 a , b}$ and $\mathbf{6 2} \mathbf{a}, \mathbf{b}$ was performed by using diisopropylethylamine (DIEA) and di-t-butyl dicarbonate $\left(\mathrm{Boc}_{2} \mathrm{O}\right)$.

\section{Deprotonation/carbamoylation of rotaxanes $\mathbf{6 1 a}, \mathbf{b}$}

Upon deprotonation/carbamoylation of rotaxanes 61a,b having extended co-conformation they shift the both rings along the thread to both ends, affording 63a (in a contracted coconformation) and $\mathbf{6 3 b}$ (in a very contracted co-conformation). In contracted co-conformation the distance between both mannosyl groups is smaller than in extended co-conformation. It is interesting that in the synthesis of $\mathbf{6 3 \mathbf { b }}$ the conformational flipping of the mannopyranose molecules from ${ }^{1} \mathrm{C}_{4}$ to ${ }^{4} \mathrm{C}_{1}$ occurs. 


\section{Example C}
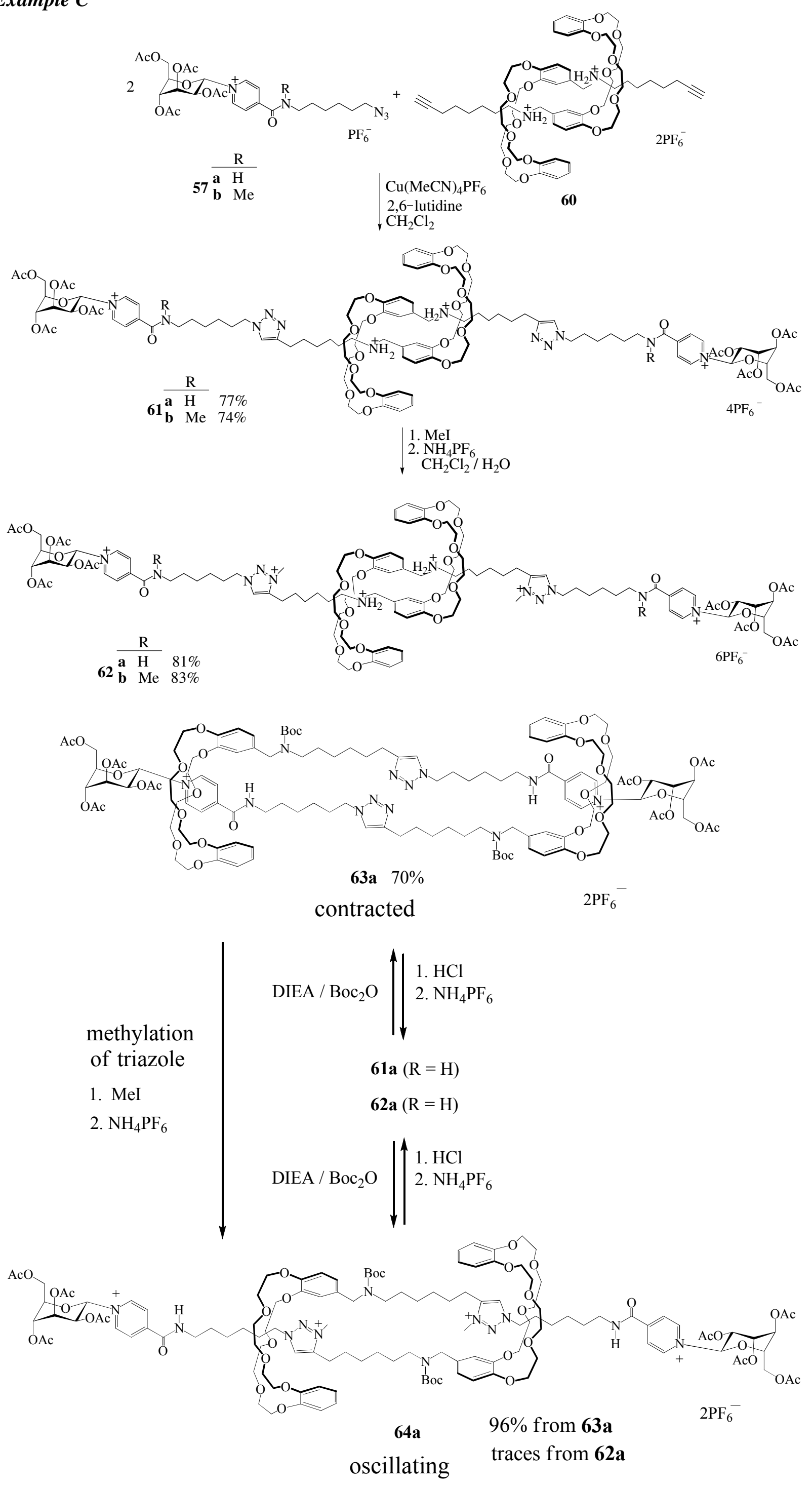


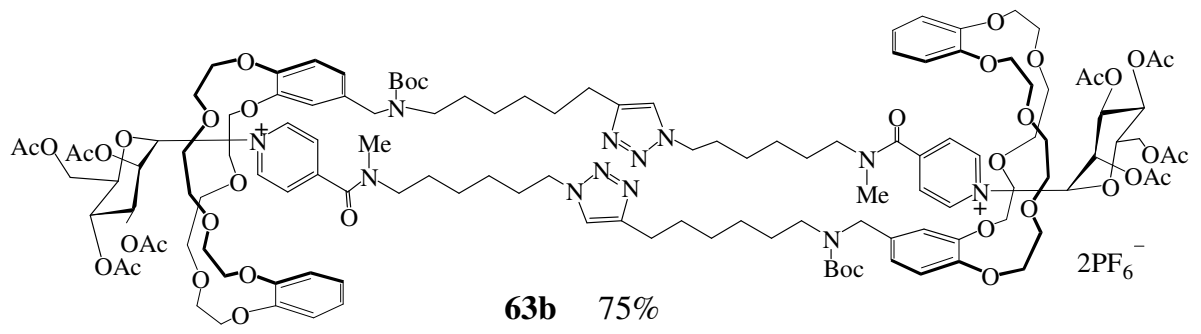

very contracted

$\left.\begin{array}{l}\text { 1. } \mathrm{HCl} \\ \text { 2. } \mathrm{NH}_{4} \mathrm{PF}_{6}\end{array}\right\rfloor$ DIEA / $\mathrm{Boc}_{2} \mathrm{O}$

61b $\mathrm{R}=\mathrm{Me}$

62b $\mathrm{R}=\mathrm{Me}$

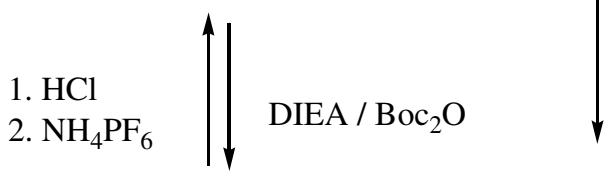

methylation

of triazole

1. $\mathrm{MeI}$

2. $\mathrm{NH}_{4} \mathrm{PF}_{6}$

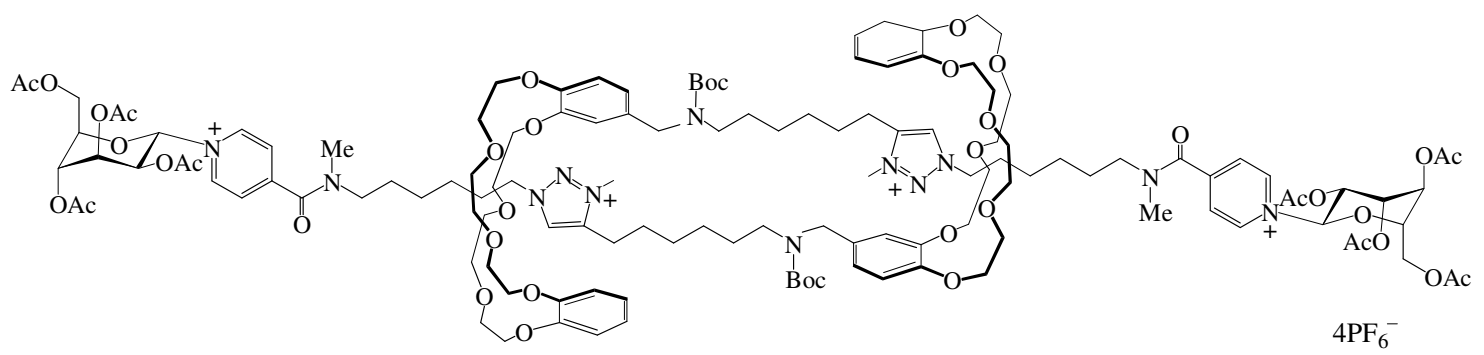

$64 b$

$91 \%$ from $\mathbf{6 3 b}$

half-contracted

$73 \%$ from $\mathbf{6 2 b}$

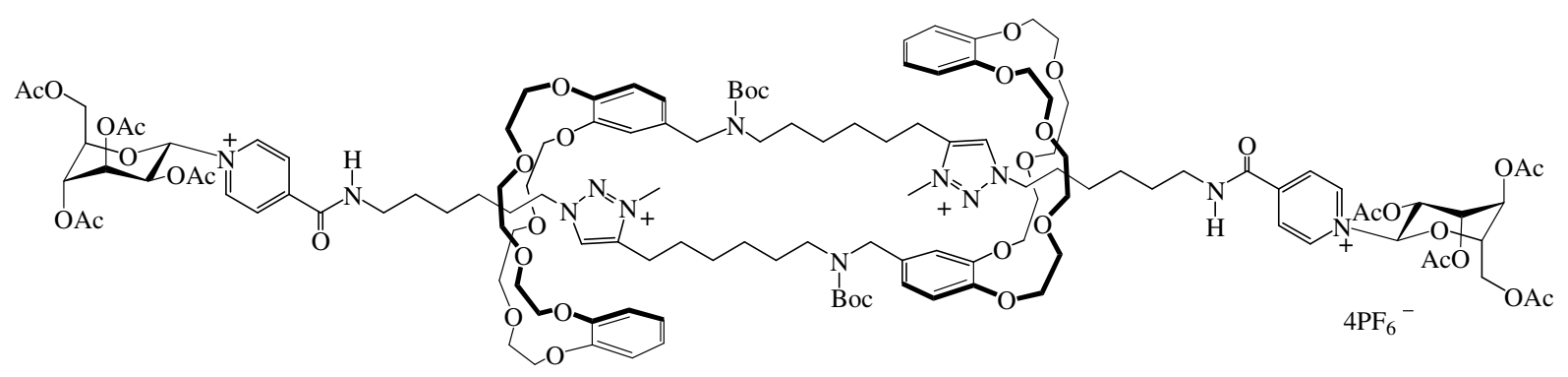

translational isomer $\mathbf{6 4 \mathbf { a } _ { 1 }}$

half - contracted

(preferred in dissociating solvents, e.g. DMSO)

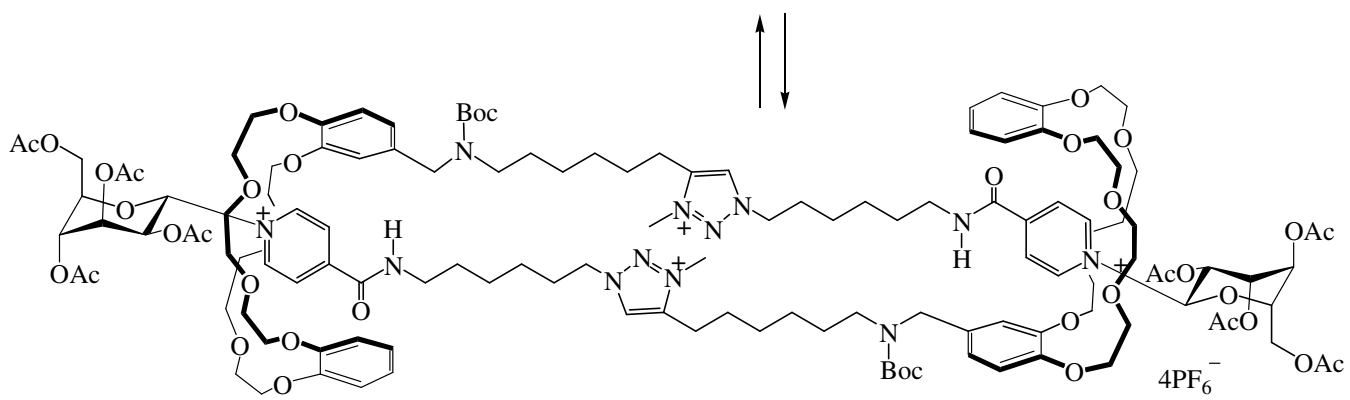

translational isomer $\mathbf{6 4 \mathbf { a } _ { 2 }}$

contracted

Scheme 15

(preferred in nondissociating solvents, e.g. $\mathrm{CDCl}_{3}$ )

Deprotonation/carbamoylation of rotaxanes $\mathbf{6 2} \boldsymbol{a}, \boldsymbol{b}$

Rotaxanes 62a,b have been subjected to similar deprotonation/carbamoylation procedure, it was found however, that $62 \mathbf{a}$ gives only traces of $\mathbf{6 4 a}$, whereas the reaction of $\mathbf{6 2 b}$ affords $64 \mathbf{b}$ in 
$73 \%$ yield. To overcome this difficulty concerning the low yield of $\mathbf{6 4 a}$, the rotaxanes $\mathbf{6 3 a , b}$ were methylated at the triazole rings to give $\mathbf{6 4 a}, \mathbf{b}$ in $c$ a $90 \%$ yields.

Upon deprotonation/carbamoylation of rotaxane $\mathbf{6 2} \mathbf{a}$, the formed $\mathbf{6 4 a}$ adopts an alterning co-conformation between a half-contracted and contracted co-conformation, the both rings shuttle between triazolium and monosubstituted pyridinium amide stations, since each ring has similar affinity to these two stations. In this way the oscillating molecular muscle was formed. It is noteworthy that the above continuous oscillation of both rings between $N$-methyltriazolium and monosubstituted pyridinium amide stations may be controlled by the variation of the solvent polarity. In dissociating solvents like DMSO the half-contracted translational co-conformer $\mathbf{6 4 \mathbf { a } _ { 1 }}$ is preferred, whereas in nondissociating solvents like $\mathrm{CDCl}_{3}$ the contracted translational isomer $\mathbf{6 4} \mathbf{a}_{2}$ is preferred.

Upon deprotonation/carbamoylation of rotaxane $\mathbf{6 2} \mathbf{b}$, however, the formed $\mathbf{6 4 b}$ adopts a half-contracted co-conformation. The both rings become situated at $N$-methyltriazolium stations, since each ring has higher affinity to $N$-methyltriazolium than to the disubstituted pyridinium amide station. $^{91}$

\section{Pseudorotaxanes containing cryptands as rings}

Pseudorotaxanes containing crown ether based cryptands (further named cryptands) as rings were not so widely investigated as those containing crown ethers. One should note that pseudorotaxanes formed from viologens and cryptands are bound more strongly than pseudorotaxanes formed from viologens and crown ethers. ${ }^{92}$ From among many syntheses of pseudorotaxanes built from viologens and cryptands, ${ }^{93-95}$ below three selected examples $1-3$ are given.

\section{Example 1}

Basing on the recognition of vinylogous viologens $\mathbf{6 5}$ and $\mathbf{6 6}$ with symmetric $A$ and asymmetric B cryptands, four [2]pseudorotaxanes were obtained. It should be pointed out that vinylogous viologens, i.e. $\pi$-extended viologens enlarge the properties of viologens, such as fluorescence and photocontrolled isomerisations, however, they are not so often as viologens used for construction of mechanically interlocked structures. ${ }^{96}$

The $K_{\mathrm{a}}$ values of investigated [2]pseudorotaxanes are high, and are comparable to the corresponding host-guest systems viologen/cryptand; they decrease in the order $\mathbf{6 5} \cdot \mathbf{A}>\mathbf{6 6} \cdot \mathbf{A}>\mathbf{6 5} \cdot \mathbf{B}>\mathbf{6 6} \cdot \mathbf{B} .^{97}$ The structure of pseudorotaxane $\mathbf{6 6} \cdot \mathbf{B}$ is shown. The X-ray analysis of the crystal structure of [2]pseudorotaxanes $65 \cdot \mathbf{A}$ and $\mathbf{6 6} \cdot \mathbf{B}$ indicates that they are stabilized by hydrogen bonding and face-to-face $\pi$-stacking interactions. The [2]pseudorotaxane $\mathbf{6 5} \cdot \mathbf{A}$ has the highest $K_{\mathrm{a}}$ value (of the $10^{6}$ range) among investigated species; it forms a supramolecular poly[2]pseudorotaxane structure in the solid state.

It was observed that the formation of [2]pseudorotaxanes $65 \cdot \mathbf{B}$ and $66 \cdot \mathbf{B}$ can be controlled by adding and removing of potassium ion. Upon addition of $\mathrm{KPF}_{6}$, cryptand $\mathbf{B}$ forms a more stable complex with $\mathrm{K}^{+}$than with $\mathbf{6 6}$, and as a result the complex $\mathbf{6 6} \cdot \mathbf{B}$ disassembles. However, when DB18C6 is added to trap the added $\mathrm{K}^{+}$, the complex $\mathbf{6 6} \cdot \mathbf{B}$ is recovered, i.e. the process is reversible. Due to this behavior, the formation of pseudorotaxane $\mathbf{6 6} \cdot \mathbf{B}$ can be switched off and on by addition of $\mathrm{KPF}_{6}$, followed by DB18C6; in this way a cation-responsive host-guest pair for design of stimuli-responsive molecular shuttles and machines was created.

The $K_{\mathrm{a}}$ value for $\mathbf{6 5} \cdot \mathbf{B}$ (of the $10^{5}$ range) is higher than that for $66 \cdot \mathbf{B}$ (of the $10^{4}$ range), therefore the reversible switch in $\mathbf{6 5} \cdot \mathbf{B}$ is more difficult than that in $\mathbf{6 6} \cdot \mathbf{B}$. This observed cationresponsive binding of vinylogous viologens 65 and 66 with $\mathbf{B}$ is promising for design of controllable molecular shuttles (Scheme 16). 


\section{Example 1}

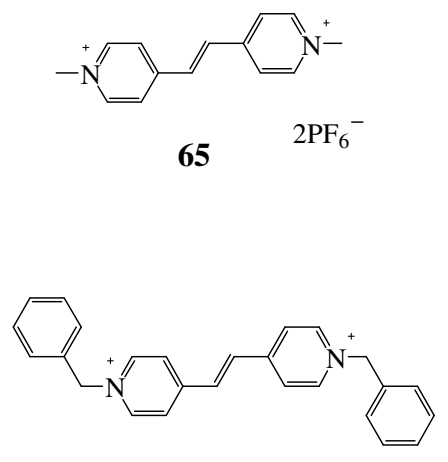

$66 \quad 2 \mathrm{PF}_{6}$

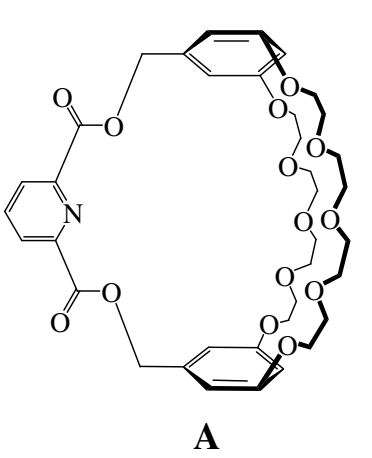

symmetric

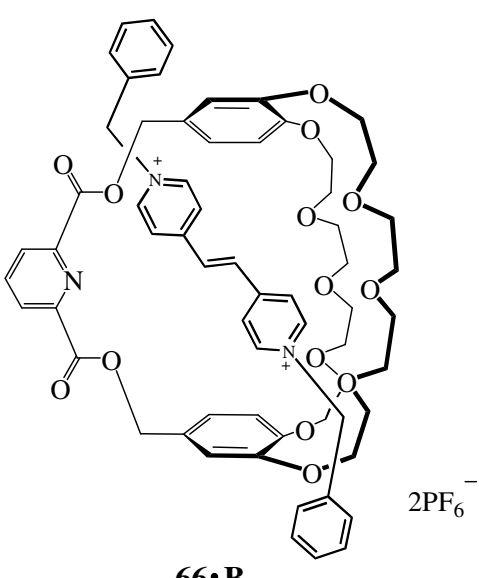

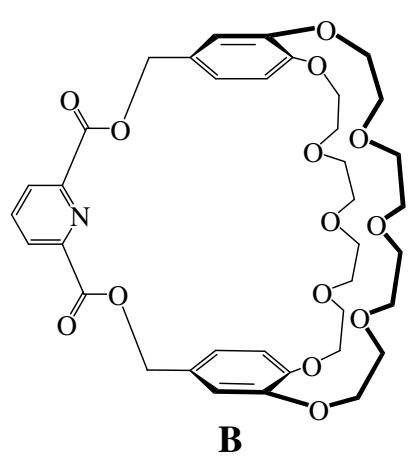

asymmetric

\section{Example 2}
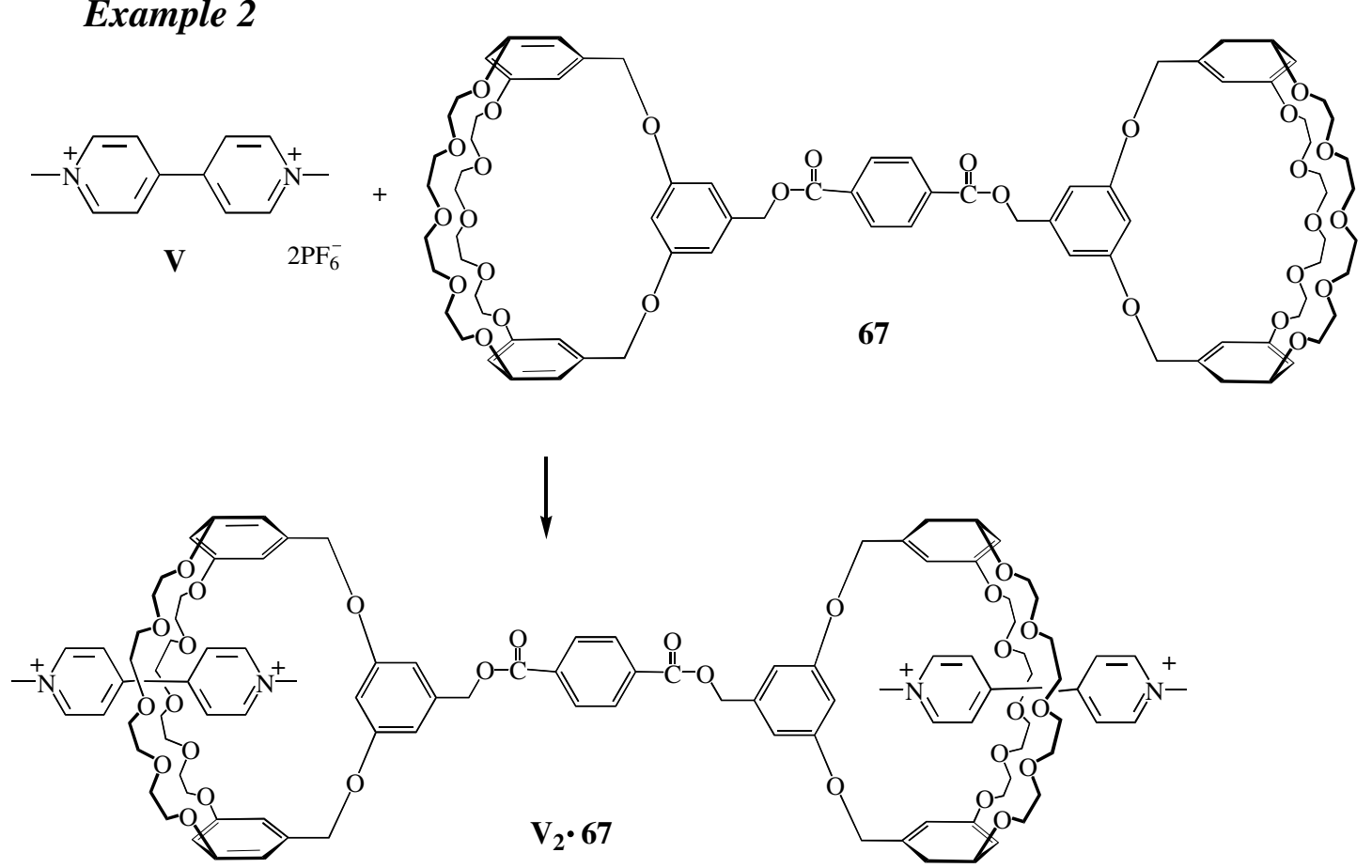

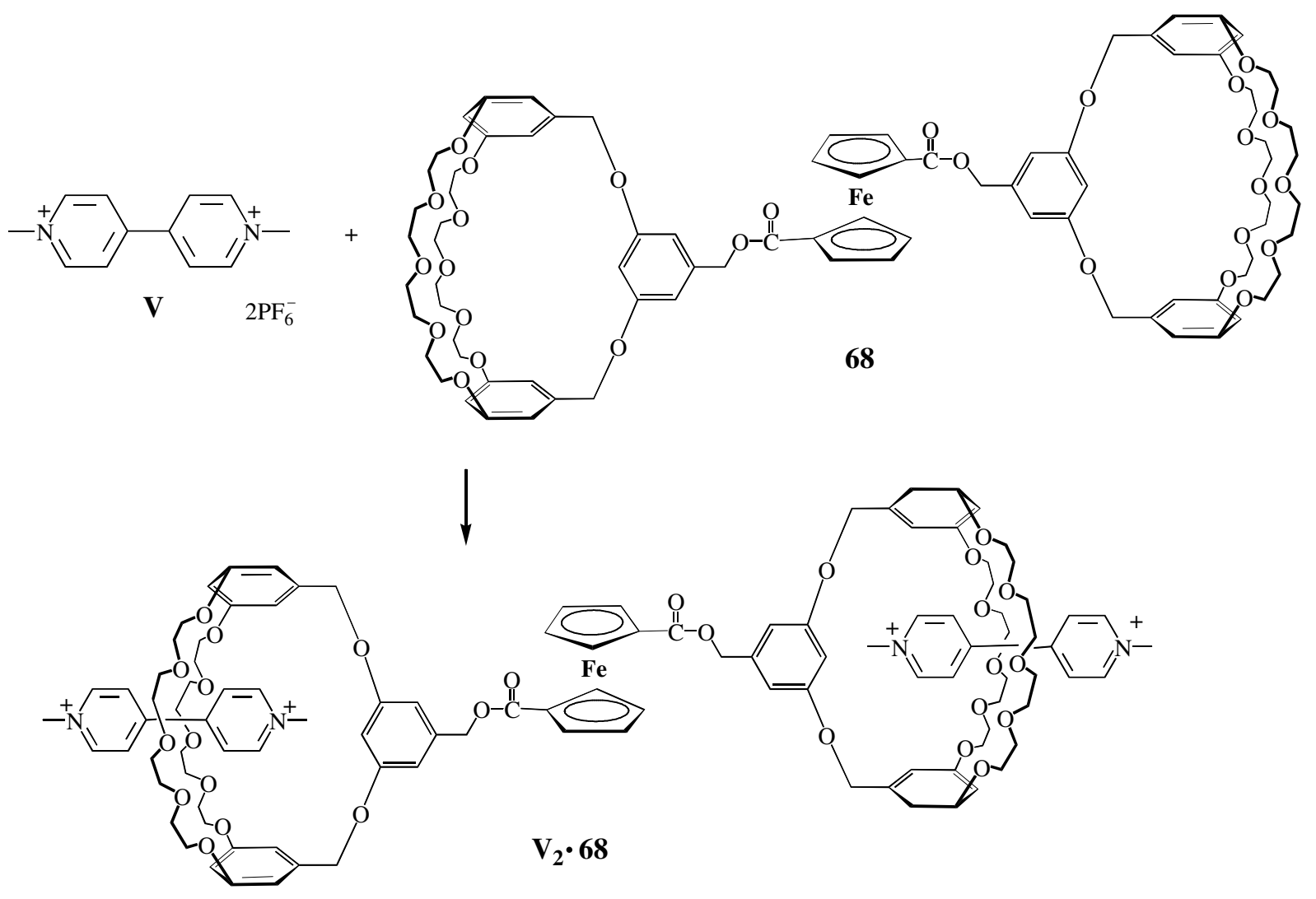

Example 3
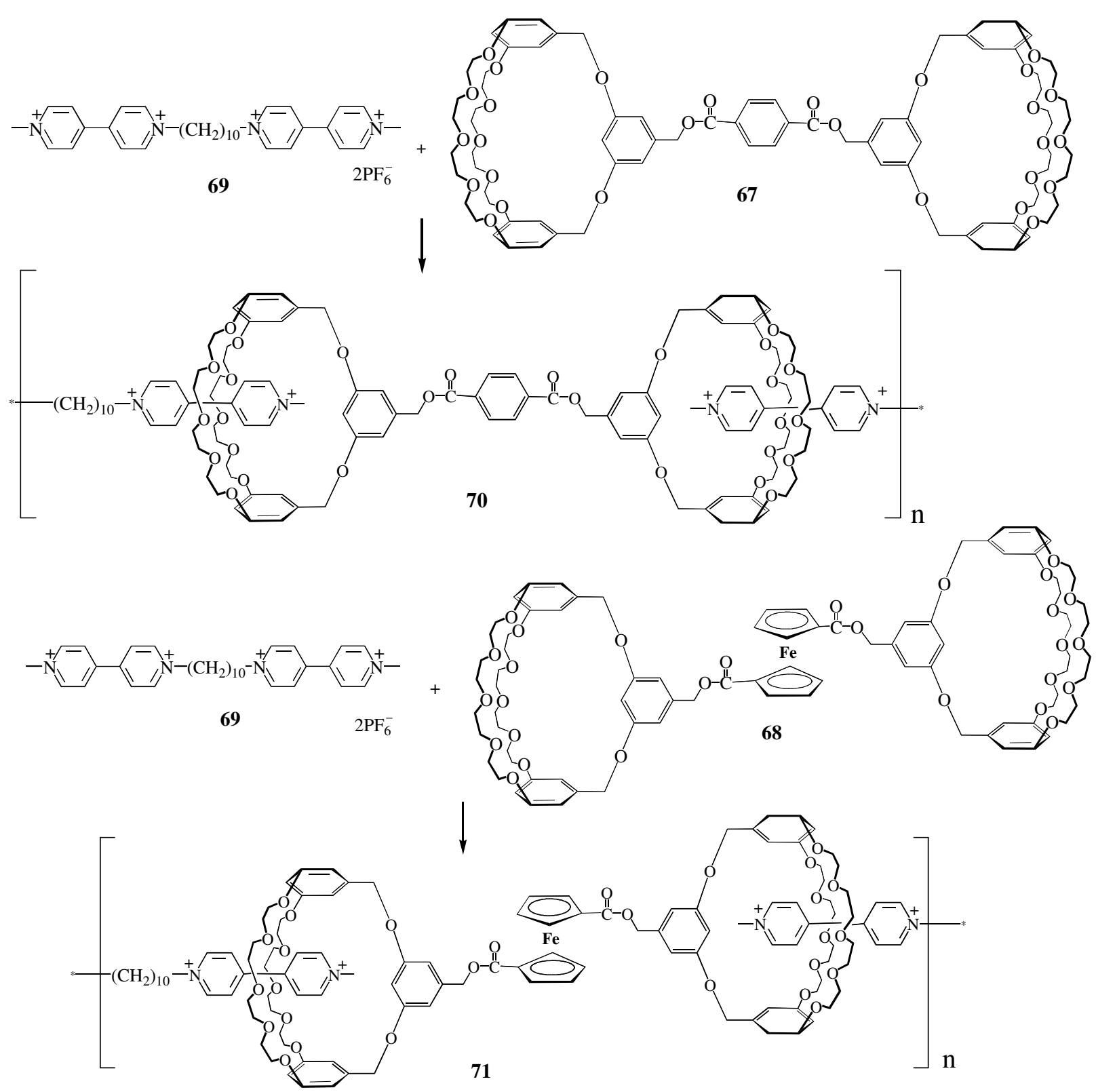

Scheme 16 


\section{Example 2}

Pseudorotaxanes $^{98}$ are important building blocks for rotaxanes, catenanes, as well as polyrotaxanes and polycatenanes. ${ }^{99,100}$ Syntheses of pseudorotaxanes from viologens and crown ethers are a topic of numerous reports, ${ }^{101-104}$ however those concerning pseudorotaxanes built from viologens and cryptands are not so largely investigated. It was found that the self-assembly of viologen $\mathbf{V}$ with biscryptand $\mathbf{6 7}$ having covalent (terephthalate) linkage and biscryptand $\mathbf{6 8}$ having metal-complex (ferrocene ester) linkage affords [3]pseudorotaxanes $\mathbf{V}_{2} \cdot \mathbf{6 7}$ and $\mathbf{V}_{\mathbf{2}} \cdot \mathbf{6 8}$ formed statistically and anticooperatively, respectively. ${ }^{105}$

The individual solutions of viologen $\mathbf{V}$ and of biscryptand 67 in $\mathrm{CDCl}_{3} /\left(\mathrm{CD}_{3}\right)_{2} \mathrm{CO}(1: 3)$ are colorless, however the solution of viologen $\mathbf{V}$ with $\mathbf{6 7}$ is yellow due to charge transfer between the electron deficient viologen $\mathbf{V}$ and electron rich aromatic rings of biscryptand 67 . The selfassembly of viologen $\mathbf{V}$ with $\mathbf{6 7}$ affords the [3]pseudorotaxane $\mathbf{V}_{\mathbf{2}} \cdot \mathbf{6 7}$.

In a similar manner the complex $\mathbf{V}_{2} \cdot \mathbf{6 8}$ was obtained. The biscryptand $\mathbf{6 8}$ is red, therefore color change resulting from charge transfer between viologen $\mathbf{V}$ and $\mathbf{6 8}$ in $\mathrm{CDCl}_{3} /\left(\mathrm{CD}_{3}\right)_{2} \mathrm{CO}$ (1:3) could not be seen. One should point out that the anticooperative formation of [3]pseudorotaxane $\mathbf{V}_{\mathbf{2}} \cdot \mathbf{6 8}$ was observed in complexations of viologens with biscryptands for the first time.

\section{Example 3}

Supramolecular polymers attract recently a growing attention. In contrast to covalent polymers, they are noncovalent, mechanically interlocked structures of promising properties. ${ }^{106-112}$ The crown ether-based, pseudorotaxane type supramolecular polymers are used in preparation of interesting structures. However it should be taken into account that for preparation of large supramolecular polymers, the monomers with high association constants are necessary.

Cryptands are much better receptors for viologens than crown ethers, therefore they have promising properties to form supramolecular polymers. It is also noteworthy that viologens, in contrast to complexation with crown ethers, leading often to taco systems, ${ }^{113}$ form with cryptands the threaded, pseudorotaxane-products. ${ }^{101,114}$

It was found that bisviologen 69 (as a BB monomer) forms with biscryptands 67 and 68 (as AA monomers) the linear noncovalent supramolecular polymers $\mathbf{7 0}$ and $\mathbf{7 1}$, respectively, of a well defined pseudorotaxane structure, having covalent (terephthalate) or metal-complex (ferrocene ester) linkages. They are of a AA-BB type and have relatively high molecular weights. ${ }^{99}$

The equimolar solution of bisviologen 69 and biscryptand 67 in chloroform/acetonitrile $(1: 1)$ is yellow due to charge transfer interaction of electron deficient pyridinium rings of 69 with electron rich aromatic rings of biscryptand 67; this fact confirms the complexation. The equimolar solution of 69 with 67 shows high specific viscosity, indicating the high association constant in this system. One should note that it is the highest specific viscosity reported for a pseudorotaxane supramolecular polymer. It was found that long thin fibers could be drawn from concentrated equimolar solutions of 69 with 67 , this observation also confirms formation of supramolecular polymer 70. Similarly, from concentrated solution of 69 with 68 also thin fibers of supramolecular polymer $\mathbf{7 1}$ could be drawn. The obtained pseudorotaxane supramolecular polymers $\mathbf{7 0}$ and $\mathbf{7 1}$ may be converted into irreversibly mechanically linked rotaxane polymers by attachment of bulky stoppers at the ends of bisviologen 69.

\section{Conclusions}

Interlocked systems, mainly rotaxanes $^{115-118}$ and catenanes ${ }^{119-122}$ as well as polyrotaxanes ${ }^{123-126}$ and polycatenanes ${ }^{127-130}$ are today intensively studied. Due to the multiplicity of works, the above described reports on rotaxanes and pseudorotaxanes with threads containing 
pyridinium units are only selected examples, however, one should hope that some light will be shed on this important area of chemistry and related sciences.

Among studies concerning this topic, a wide research leading to design of molecular machines ${ }^{131,132}$ exists, therefore development of this field may be expected. ${ }^{133,134}$ Worth noting are here rotacatenanes ${ }^{133}$ which are a combination of rotaxanes and catenanes, promising for construction of molecular machines.

Taking into account a rapid progress of supramolecular chemistry research, one should point out a growing attention paid today to foldamers. ${ }^{134-136}$ They are helical receptors for rod-like guest molecules. It was found that double helical foldamers coiled around rod-shaped guest molecules can perform a screw-type motion, which does not occur in other molecular machines. ${ }^{137,138}$

Foldamer-based rotaxanes named foldaxanes ${ }^{139}$ may form stable, double-helical structures via hydrogen-bonding and $\pi$-stacking interactions. Foldaxanes are obtained by unfolding/refolding mechanism of a high kinetic barrier, therefore they have relatively high stability.

It has been observed that in foldaxanes, in which rods have different helix-binding sites, the shuttling proceeds faster than the disassembly of the foldaxane. ${ }^{140}$ In other words, it has been established that the action of these nanomachines is much faster than their assembly/disassembly process, similarly as in the case of "biomachines". One may believe that the above results will be useful in future for construction of molecular machines. ${ }^{134,135}$

\section{Acknowledgements}

The work is a part of the project no. N N209 441539. The authors gratefully acknowledge Polish Ministry of Science along with Higher Education and National Science Centre for financial support of this project.

\section{References}

1. Dasgupta, S.; Huang, K.-W.; Wu, J. Chem. Commun. 2012, 48, 4821.

http://dx.doi.org/10.1039/c2cc31009k

PMid:22498508

2. Zhu, K.; Vukotic, V. N.; Loeb, S. J. Angew. Chem. Int. Ed. 2012, 51, 2168.

http://dx.doi.org/10.1002/anie.201108488

PMid:22259027

3. Joosten, A.; Trolez, Y.; Collin, J.-P.; Heitz, V.; Sauvage, J-P. J. Am. Chem. Soc. 2012, 134, 1802.

http://dx.doi.org/10.1021/ja210113y

PMid:22236438

4. Yamada, Y.: Okamoto, M.; Furukawa, K.; Kato, T.; Tanaka, K. Angew. Chem. Int. Ed. 2012, 51, 709.

http://dx.doi.org/10.1002/anie.201107104

PMid:22134904

5. Evans, N. H.; Beer, P. D. In Supramolecular Chem. From Molecules to Nanomaterials, Eds. Gale, P.; Steed, J. John Wiley: New York, 2012; p 2225.

6. Ayme, J.-F.; Lux, J.; Sauvage, J.-P.; Sour, A. Chem. Eur. J. 2012, 18, 5565. http://dx.doi.org/10.1002/chem.201104061

PMid:22431359

7. Elbaz, J.; Wang, Z.-G.; Wang, F.; Willner, I. Angew. Chem. Int. Ed. 2012, 51, 2349. http://dx.doi.org/10.1002/anie.201107591

PMid:22287100 
8. Strutt, N. L.; Zhang, H.; Giesener, M. A.; Lei, J.; Stoddart, J. F. Chem. Commun. 2012, 48, 1647.

http://dx.doi.org/10.1039/c2cc16030g

PMid:22187005

9. Zheng, B.; Zhang, M.; Dong, S.; Liu, J.; Huang, F.; Org. Letters 2012, 14, 306.

http://dx.doi.org/10.1021/ol203062w

PMid:22148951

10. Beves, J. E. Chimia 2012, 66, 170.

http://dx.doi.org/10.2533/chimia.2012.170

PMid:22613142

11. Keene, F. R. In Supramolecular Chemistry; From Molecules to Nanomaterials, Eds. P. Gale, P.; Steed, J. Wiley: New York, 2012; pp 217. PMid:22413819.

12. Venturi, M.; Marchi, E.; Balzani, V. Top. Curr. Chem. 2012, 323, 73. http://dx.doi.org/10.1007/128_2011_293

PMid:22076080

13. Hänni, K. D.; Leigh, D. A. Chem. Soc. Rev. 2010, 39, 1240.

http://dx.doi.org/10.1039/b901974j

PMid:20309484

14. Vukotic, V. N.; Harris, K. J.; Zhu, K.; Schurko, R. W.; Loeb, S. J. Nature Chem. 2012, 4, 456.

http://dx.doi.org/10.1038/nchem.1354 PMid:22614379.

15. Took, C.; Frey, J.; Sauvage, J. P. In Molecular Switches, Eds. Feringa, B. L.; Browne, W. R.; Wiley: New York, Vol. 1, 2011; p 97. http://dx.doi.org/10.1002/9783527634408.ch4

16. Noujeim, N.; Zhu, K.; Vukotic, V. N.; Loeb, S. J. Org. Letters 2012, 14, 2484. http://dx.doi.org/10.1021/o1300761q PMid:22551383.

17. Yan, X., Wei, P.; Xia, B.; Huang, F.; Zhou, Q. Chem. Commun. 2012, 48, 4968. http://dx.doi.org/10.1039/c2cc31374j PMid:22497011

18. Loew, N. L.; Dzyuba, E. V.; Brusilowskij, B.; Kaufmann, L.; Franzmann, E.; Maison, W.; Brandt, E.; Aicher, D.; Wiehe, A.; Schalley, C. A. Beilstein J. Org. Chem. 2012, 8, 234. http://dx.doi.org/10.3762/bjoc.8.24 PMid:22423290 PMCid:3302084

19. Mlika, R.; Hbaieb, S.; Ben Chaabene, R.; Chevalier, Y.; Kalfat, R.; Ben Quada, H. Synthetic Met. 2012, 162, 186.

http://dx.doi.org/10.1016/j.synthmet.2011.11.029

20. Fu, Q.; Ren, J. M.; Qiao, G. G. Polym. Chem. 2012, 3, 343. http://dx.doi.org/10.1039/c1py00362c

21. Bang, E.-K.; Lista, M.; Sforazzini, G.; Sakai, N.; Matile, S. Chem. Sci. 2012, 3, 1752. http://dx.doi.org/10.1039/c2sc20098h

22. Yui, N. In Supramolecular Polymer Chemistry, Ed. Harada, A. Wiley - VCH: New York, 2012; p 195.

http://dx.doi.org/10.1002/9783527639786.ch9

23. Yamada, Y.; Nomura, T.; Harashima, H.; Yamashita, A.; Yui, N. Biomaterials 2012, 33, 3952.

http://dx.doi.org/10.1016/j.biomaterials.2012.01.049 PMid:22386920.

24. Deligkiozi, I.; Papadakis, R.; Tsolomitis, A. Supramol. Chem. 2012, 24, 333. http://dx.doi.org/10.1080/10610278.2012.660529

25. Akae, Y.; Okamura, H.; Koyama, Y.; Arai, T.; Takata, T. Org. Letters 2012, 14, 2226. http://dx.doi.org/10.1021/ol300578q

PMid:22519824 
26. Zhu, L.; Yan, H.; Nguyen, K. T.; Tian, H.; Zhao, Y. Chem. Commun. 2012, 48, 4290. http://dx.doi.org/10.1039/c2cc17114g PMid:22301771

27. Girek T. J. Incl. Phenom. Macrocycl. Chem. 2012, 74, 1. http://dx.doi.org/10.1007/s10847-012-0112-1

28. Talotta, C.; Gaeta, C.; Neri, P. Org. Lett. 2012, 14, 3104. http://dx.doi.org/10.1021/o13011997 PMid:22668501

29. Wu, S.-F.; Ma, X. Tetraedron. Lett. 2011, 52, 5960. http://dx.doi.org/10.1016/j.tetlet.2011.08.129

30. Sinha, M.K.; Reany, O.; Yefet, M.; Botoshansky, M.; Keinan, E. Chem. Eur. J. 2012, 18, 5589.

http://dx.doi.org/10.1002/chem.201103434 PMid:22434704.

31. Kolman, V.; Khan, M. S. A., Babinsky, M.; Marek, R.; Sindelar, V. Org. Lett. 2011, 13, 6148.

http://dx.doi.org/10.1021/ol2023888 PMid:22066799.

32. Liu, P.; Chipot, C.; Shao, X.; Cai, W. J. Phys. Chem. C 2012, 116, 4471.

33. Kiguchi, M.; Nakashima, S.; Tada, T.; Watanabe, S.; Tsuda, S.; Tsuji, Y.; Terao, J. Small 2012, 8, 726.

$\underline{\text { http://dx.doi.org/10.1002/smll.201102075 }}$ PMid:22223591

34. Przybylski, C.; Bonnet, V.; Jarroux, N. Macro Lett. 2012, 1, 533. http://dx.doi.org/10.1021/mz3000607

35. Zhou, Y.; Wang, H.; Wang, Ch.; Li, Y.; Lu, W.; Chen, S.; Luo, J.; Jiang, Y.; Chen, J. Molecular Pharm. 2012, 9, 1067.

36. Albuzat, T.; Keil, M.; Ellis, J.; Alexander, C.; Wenz, G. J. Mater. Chem. 2012, 22, 8558. http://dx.doi.org/10.1039/c2jm16425f

37. Cragg, P. J.; Sharma, K. Chem. Soc. Rev. 2012, 41, 597. http://dx.doi.org/10.1039/c1cs15164a PMid:21804967

38. Ogoshi, T.; Kitajima, K.; Aoki, T.; Yamagishi, T. A.; Nakamoto, Y. J. Phys. Chem. Lett. 2010, $1,817$. http://dx.doi.org/10.1021/jz900437r

39. Ogoshi, T.; Nishida, Y.; Yamagishi, T. A.; Nakamoto, Y. Macromolecules 2010, 43, 7068. http://dx.doi.org/10.1021/ma101320z

40. Ma, Y.; Chi, X.; Yan, X.; Liu, J.; Yao, Y.; Chen, W.; Huang, F.; Hou, J.-L. Org. Lett. 2012, 14,1532 .

http://dx.doi.org/10.1021/ol300263z PMid:22401142.

41. Xue, M.; Yang, Y.; Chi, X.; Zhang, Z.; Huang, F. Acc. Chem. Res. 2012, 45, 1294. http://dx.doi.org/10.1021/ar2003418 PMid:22551015

42. Li, C.; Xu, Q.; Li, J.; Yao, F.; Jia, X. Org. Biomol. Chem. 2010, 8, 1568. http://dx.doi.org/10.1039/b920146g PMid:20336850

43. Li, C. J.; Zhao, L.; Li, J. A.; Ding, X.; Chen, S. H.; Zhang, Q. L.; Yu, Y. H.; Jia, X. S. Chem. Commun. 2010, 46, 9016. http://dx.doi.org/10.1039/c0cc03575k PMid:21057678.

44. Deska, M.; Kozlowska, J.; Sliwa, W. Arkivoc, in press.

45. Sliwa, W.; Bachowska, B.; Girek, T. Curr. Org. Chem. 2012,16, 1332. http://dx.doi.org/10.2174/138527212800564240 
46. Sliwa, W.; Chrzastek, L. Curr. Org. Chem. 2009,13, 339. http://dx.doi.org/10.2174/138527209787582295

47. Mercer, D. J.; Vella, S. J.; Guertin, L.; Suhan, N. D.; Tiburcio, J.; Vukotic, V. N.; Wisner, J. A.; Loeb, S. J. Eur. J. Org. Chem. 2011, 1763.

http://dx.doi.org/10.1002/ejoc.201001616

48. Tramontozzi, D. A.; Suhan, N. D.; Eichhorn, S. H.; Loeb, S. J. Chem. Eur. J. 2010, 16, 4466.

http://dx.doi.org/10.1002/chem.200903174

PMid:20352637.

49. Suzuki, S.; Nakazono, K.; Takata, T. Org. Lett. 2010, 12, 712.

http://dx.doi.org/10.1021/o1902719m

PMid:20088538

50. Vella, S. J.; Tiburcio, J.; Loeb, S. J. Chem. Commun. 2007, 4752. http://dx.doi.org/10.1039/b710708k

PMid:18004430

51. Zhao, J.-M.; Zong, Q.-S.; Han, T.; Xiang, G.-F.; Chen, C.-F. J. Org. Chem. 2008, 73, 6800. http://dx.doi.org/10.1021/jo801170t PMid:18672935

52. Zhang, C.; Chen, C.-F. J. Org. Chem. 2007, 72, 9339. http://dx.doi.org/10.1021/jo7017526 PMid:17958375

53. Lin, C.-F.; Lai, C.-C.;Liu, Y.-H.; Peng, S.-M.; Chiu, S.-H. Chem. Eur. J. 2007, 13, 350. http://dx.doi.org/10.1002/chem.200601432 PMid: 17323386

54. Rit, A.; Pape, T.; Hepp, A.; Hahn, F.E. Organometallics 2011, 30, 334. http://dx.doi.org/10.1021/om101102j

55. Rit, A.; Pape, T.; Hahn, F. E. J. Am. Chem. Soc. 2010, 132, 4572. http://dx.doi.org/10.1021/ja101490d PMid:20222710

56. Conrady, F. M.; Fröhlich, R.; Schulte to Brinke, C.; Pape, T.; Hahn, F. E. J. Am. Chem. Soc. 2011, 133, 11496. http://dx.doi.org/10.1021/ja205021p PMid:21728329

57. Yuan, D. Y.; Huynh, H. V. Organometallics 2010, 29, 6020. http://dx.doi.org/10.1021/om1008023

58. Huynh, H. V.; Sim, W.; Chin, C. F. Dalton Trans. 2011, 40, 11/690.

59. Han, Y.; Huynh, H. V.; Tan, G. K. J. Organomet. Chem. 2007, 26, 6447. http://dx.doi.org/10.1021/om700753d

60. Knight L. K.; Vukotic, V. N.; Viljoen, E.; Caputo, C.; Loeb, S. J. Chem. Commun. 2009, 5585 .

http://dx.doi.org/10.1039/b911889f

PMid:19753365

61. Mohamadin, M. I; Abdullah, N. Int. J. Phys. Sci. 2011, 6, 2526.

62. Gassensmith, J. J.; Matthys, S.; Lee, J. J.; Wojcik, A.; Karnat, P. V.; Smith, B. D. Chem. Eur. J. 2010, 16, 2916.

http://dx.doi.org/10.1002/chem.200902547

PMid:20082394

63. McConnell, A. J.; Serpell, C. J.; Thompson, A. L.; Allan, D. R.; Beer, P. D. Chem. Eur. J. 2010, 16, 1256

http://dx.doi.org/10.1002/chem.200902659 PMid:19950342

64. Zapata, F.; Caballero, A.; Tarraga, A.; Molina, P. J. Org. Chem. 2010, 75, 162. http://dx.doi.org/10.1021/jo9023446 PMid:19968276 
65. Willener, Y.; Joly, K. A.; Moody, C. J.; Tucker, J. H. R. J. Org. Chem. 2008, 73, 1225 http://dx.doi.org/10.1021/jo701809b PMid:18205379

66. Evans, N. H.; Serpell, C. J.; White, N. G.; Beer, P. D. Chem. Eur. J. 2011, 17, 12347. http://dx.doi.org/10.1002/chem.201101811 PMid:21953676

67. Evans, N. H.; Beer, P. D. Org. Biomol. Chem. 2011, 9, 92. http://dx.doi.org/10.1039/c0ob00458h PMid:21063586

68. Brown, A.; Beer, P. D. Dalton Trans. 2012, 41, 118. http://dx.doi.org/10.1039/c1dt11372k

PMid:22075843

69. Lee, C. H.; Yoon, H.; Kim, P.; Cho, S.; Kim, D.; Jang, W. D. Chem. Commun. 2011, 47, 4246.

http://dx.doi.org/10.1039/c1cc00112d PMid:21350745

70. Lee, C. H.; Yoon, H.; Jang, W. D. Chem. Eur. J. 2009, 15, 9972. http://dx.doi.org/10.1002/chem.200901988 PMid:19722242

71. Hancock, L. M.; Beer, P. D. Chem. Eur. J. 2009, 15, 42. http://dx.doi.org/10.1002/chem.200802029 PMid:19040231

72. Hancock, L. M.; Gilday, L. C.; Carvalho, S.; Costa, P. J.; Félix, V.; Serpell, C. J.; Kilah, N. L.; Beer, P. D. Chem. Eur. J. 2010, 16, 13082. http://dx.doi.org/10.1002/chem.201002076 PMid:21031371

73. Collin, J.-P.; Frey, J.; Heitz, V.; Sauvage, J.-P.; Tock, C.; Allouche, L. J. Am. Chem. Soc. 2009, 131, 5609 .

http://dx.doi.org/10.1021/ja900565p PMid:19334735

74. Brown, A.; Mullen, K. M.; Ryu, J.; Chmielewski, M. J.; Santos, S. M.; Félix, V.; Thompson, A. L.; Warren, J. E.; Pascu, S. I.; Beer, P. D. J. Am. Chem. Soc. 2009, 131, 4937.

http://dx.doi.org/10.1021/ja809905x PMid:19296631

75. Gibson, H. W.; Yamaguchi, N.; Niu, Z.; Jones, J. W.; Slebodnick, C.; Rheingold, A. L.; Zakharov, L. N. J. Polym. Sci. Part. A; Polym. Chem. 2010, 48, 975. http://dx.doi.org/10.1002/pola.23861

76. McConnell, A. J.; Beer, P. D. Chem. Eur. J. 2011, 17, 2724. http://dx.doi.org/10.1002/chem.201002528 PMid:21264965

77. Ng, K.-Y.; Félix, V.; Santos, S. M.; Reesa, N. H.; Beer, P. D. Chem. Commun. 2008, 1281. http://dx.doi.org/10.1039/b719304a

PMid:18389107

78. Barrel, M. J.; Leigh, D. A.; Lusby, P. J.; Slavin, A. M. Z. Angew. Chem. Int. Ed. 2008, 47, 8036.

http://dx.doi.org/10.1002/anie.200802745

PMid:18792909

79. Griffiths, K. E.; Stoddart, J. F. Pure Appl. Chem. 2008, 80, 485. http://dx.doi.org/10.1351/pac200880030485

80. Juluri, B. K.; Kumar, A. S.; Liu,Y.; Ye, T.; Yang, Y.-W.; Flood, A. H.; Stoddart, J. F.; Weiss, P. S.; Huang, T. J. ACS Nano 2009, 3, 291.

http://dx.doi.org/10.1021/nn8002373

PMid:19236063 
81. Li, D.; Paxton, W. F.; Baughman, R. H.; Huang, T. J.; Stoddart, J. F.; Weiss, P. S. MR Bull. 2009, 34, 671 .

http://dx.doi.org/10.1557/mrs2009.179

82. Du, L.; Liao, S. J.; Khatib, H. A.; Stoddart, J. F.; Zink, J. I. J. Am. Chem. Soc. 2009, 131, 15136.

http://dx.doi.org/10.1021/ja904982j

PMid:19799420

83. Chwalek, M.; Auzély, R.; Fort, S. Org. Biomol. Chem. 2009, 7, 1680.

http://dx.doi.org/10.1039/b822976g

PMid:19343257

84. Chen, N.-C.; Lai, C.-C.; Liu, Y.-H.; Peng, S.-M.; Chiu, S.-H. Chem. Eur. J. 2008, 14, 2904. http://dx.doi.org/10.1002/chem.200701854

PMid:18213659

85. Coutrot, F.; Romuald C.; Busseron E. Org. Lett. 2008, 10, 3741.

http://dx.doi.org/10.1021/ol801390h

PMid:18666774

86. Coutrot, F.; Busseron E. Chem. Eur. J. 2008, 14, 4784.

http://dx.doi.org/10.1002/chem.200800480

PMid:18409178

87. Coutrot F.; Busseron E. Chem. Eur. J. 2009, 15, 5186.

http://dx.doi.org/10.1002/chem.200900076

PMid:19229918

88. Busseron, E.; Romuald, C.; Coutrot F. Chem. Eur. J. 2010, 16, 10062.

http://dx.doi.org/10.1002/chem.201000777

PMid:20607770

89. Ueng, S. H.; Hsueh, S. Y.; Lai, C. C.; Liu, Y. H.; Peng, S. M.; Chiu, S. H. Chem. Commun. 2008, 817.

http://dx.doi.org/10.1039/b716331b

PMid:18253514

90. Dawson, R. E.; Lincoln, S. F.; Easton, C. J. Chem. Commun. 2008, 3980.

http://dx.doi.org/10.1039/b809014a

PMid:18758599

91. Romuald C.; Busseron E.; Coutrot, F. J. Org. Chem. 2010, 75, 6516.

http://dx.doi.org/10.1021/jo101234u

PMid:20815375

92. Wang, F.; Zhou, Q.; Zhu, K.; Li, S.; Wang, C.; Liu, M.; Li, N.; Fronczek, F. R,; Huang, F. Tetrahedron 2009, 65, 1488.

http://dx.doi.org/10.1016/j.tet.2008.11.081

93. Liu, M.; Li, S.; Hu, M.; Wang, F.; Huang, F. Org. Lett. 2010, 12, 760.

http://dx.doi.org/10.1021/o19028463

PMid:20092356

94. Zhu, K.; Wu, L.; Yan, X.; Zheng, B.; Zhang, M.; Huang, F. Chem. Eur. J. 2010, 16, 6088. PMid:20391577.

95. Liu, M.; Yan, X.; Hu, M.; Chen, X.; Zhang, M.; Zheng, B.; Hu, X.; Shao, S.; Huang, F. Org. Lett. 2010, 12, 2558.

http://dx.doi.org/10.1021/ol100770j

PMid:20465232

96. Yan, X.; Zhang, M.; Wei, P.; Zheng, B.; Chi, X.; Ji, X.; Huang, F. Chem. Commun. 2011, 47, 9840.

http://dx.doi.org/10.1039/c1cc13472h

PMid:21808783

97. Yan, X.; Wei, P.; Zhang, M.; Chi, X.; Liu, J.; Huang, F. Org. Lett. 2011, 13, 6370.

http://dx.doi.org/10.1021/ol202657s

PMid:22077161 
98. Durola, F.; Sauvage, J.-P.; Wenger, O. S. Coord. Chem. Rev. 2010, 254, 1748. http://dx.doi.org/10.1016/j.ccr.2009.09.034

99. Niu, Z.; Huang, F.; Gibson, H. W. J. Am. Chem. Soc. 2011, 133, 2836.

http://dx.doi.org/10.1021/ja110384v

PMid:21309571

100. Fang, L.; Olson, M. A.; Benitez, D.; Tkatchouk, E.; Goddard III, W. A.; Stoddart, J. F. Chem. Soc. Rev. 2010, 39, 17.

http://dx.doi.org/10.1039/b917901a

PMid:20023833

101. Zhang, M.; Zhu, K.; Huang, F. Chem. Commun. 2010, 46, 8131. http://dx.doi.org/10.1039/c0cc02717k

PMid:20830438

102. Wang, C.; Olson, M. A.; Fang, L.; Benitez, D.; Tkatchouk, E.; Basu, S.; Basuray, A. N.; Zhang, D.; Zhu, D.; Goddard, W. A.; Stoddart, J. F. Proc. Natl. Acad. Sci. U.S.A. 2010, 107, 13991.

http://dx.doi.org/10.1073/pnas.1009302107

PMid:20663950 PMCid:2922539

103. Trabolsi, A.; Fahrenbach, A. C.; Dey, S. K.; Share, A. I.; Friedman, D. C.; Basu, S.; Gasa, T. B.; Khashab, N. M.; Saha, S.; Aprahamian, I.; Khatib, H. A.; Flood, A. H.; Stoddart, J.

F. Chem. Commun. 2010, 46, 871.

http://dx.doi.org/10.1039/b918321c PMid:20107634

104. Jiang, Y.; Cao, J.; Zhao, J.-M.; Xiang, J.-F.; Chen, C.-F. J. Org. Chem. 2010, 75, 1767. http://dx.doi.org/10.1021/jo902571n PMid:20136155

105. Niu, Z.; Gibson, H. W. Org. Biomol. Chem. 2011, 9, 6909. http://dx.doi.org/10.1039/c1ob06299a PMid:21870005

106. Xu, D.; Hawk, J. L.; Loveless, D. M.; Jeon, S. L.; Craig, S. L. Macromolecules 2010, 43, 3556.

http://dx.doi.org/10.1021/ma100093b PMid:20479956 PMCid:2869658

107. Pensec, S.; Nouvel, N.; Guilleman, A.; Creton, C.; Boué, F. O.; Bouteiller, L. Macromolecules 2010, 43, 2529. http://dx.doi.org/10.1021/ma901709e

108. Burattini, S.; Greenland, B. W.; Merino, D. H.; Weng, W.; Seppala, J.; Colquhoun, H. M.; Hayes, W.; Mackay, M. E.; Hamley, I. W.; Rowan, S. J. J. Am. Chem. Soc. 2010, 132, 12051.

http://dx.doi.org/10.1021/ja104446r PMid:20698543

109. Rancatore, B. J.; Mauldin, C. E.; Tung, S.-H.; Wang, C.; Hexemer, A.; Strzalka, J.; Fréchet, J. M. J.; Xu, T. ACS Nano 2010, 4, 2721. $\underline{\text { http://dx.doi.org/10.1021/nn100521f }}$ PMid:20402495

110. Tancini, F.; Yebeutchou, R. M.; Pirondini, L.; De Zorzi, R.; Geremia, S.; Scherman, O. A.; Dalcanale, E. Chem. Eur. J. 2010, 16, 14313.

http://dx.doi.org/10.1002/chem.201002237 PMid:21125623

111. Greuel, J. R.; Andrews, T. E.; Wichman, J. J.; Tessner, J. D.; Wiegel, K. N. Liq. Cryst. 2010, 37, 1515. http://dx.doi.org/10.1080/02678292.2010.531404

112. Li, S.; Zheng, B.; Chen, J.; Dong, S.; Ma, Z.; Huang, F.; Gibson, H. W. J. Polym. Sci. Part A; Polym. Chem. 2010, 48, 4067. http://dx.doi.org/10.1002/pola.24192 
113. Li, S.; Liu, M.; Zheng, B.; Zhu, K.; Wang, F.; Li, N.; Zhao, X.-L.; Huang, F. Org. Lett. 2009, 11, 3350.

http://dx.doi.org/10.1021/o19012052

PMid:19572601

114. Li, S.; Zheng, B.; Huang, F.; Zakharov, L.; Slebodnick, C.; Rheingold, A.; Gibson, H. W.

Sci. China Chem. 2010, 53, 858.

http://dx.doi.org/10.1007/s11426-010-0120-1

115. Chen, N.-C.; Chuang, C.-J.; Wang, L.-Y.; Lai, C.-C.; Chiu, S.-H. Chem. Eur. J. 2012, 18, 1896.

http://dx.doi.org/10.1002/chem.201103464

PMid:22249948

116. Coskun, A.; Hmadeh, M.; Barin, G.; Gándara, F.; Li, Q.; Choi, E.; Strutt, N. L.; Cordes, D. B.; Slawin, A. M. Z.; Stoddart, J. F.; Sauvage, J.-P., Yaghi, O. M. Angew. Chem. Inter. Ed. 2012, 51, 2160 .

117. Gibson, H. W.; Wang, H.; Niu, Z.; Slebodnick, C.; Zhakharov, L. N.; Rheingold, A. L. Macromolecules 2012, 45, 1270.

http://dx.doi.org/10.1021/ma202373x

118. Avellini, T.; Li, H.; Coskun, A.; Barin, G.; Trabolsi, A.; Basuray, A. N.; Dey, S. K.; Credi, A.; Silvi, S.; Stoddart, J. F., Venturi, M. Angew. Chem. Inter. Ed. 2012, 51, 1611.

119. Capdevila-Cortada, M.; Novoa, J. J. Chem. Eur. J. 2012, 18, 5335.

http://dx.doi.org/10.1002/chem.201103550

PMid:22431244

120. Yamaguchi, H.; Harada, A. in Supramolecular Polymer Chemistry, Ed. Harada, A. Wiley VCH: New York, 2012; p 127. http://dx.doi.org/10.1002/9783527639786.ch6

121. Xiao, T.; Li, S.-L.; Zhang, Y.; Lin, C.; Hu, B.; Guan, X.; Yu, Y.; Jiang, J.; Wang, L. Chem. Sci. 2012, 3, 1417. http://dx.doi.org/10.1039/c2sc01004f

122. Sannohe, Y.; Sugiyama, H. Bioorg. Med. Chem. 2012, 20, 2030. http://dx.doi.org/10.1016/j.bmc.2012.01.040 PMid:22364954

123. Ito, K. Polymer J. 2012, 44, 38. http://dx.doi.org/10.1038/pj.2011.85

124. Inoue, Y.; Ye, L.; Ishihara, K.; Yui, N. Colloids Surfaces B 2012, 89, 223. http://dx.doi.org/10.1016/j.colsurfb.2011.09.020 PMid:21974908

125. Yamada, Y.; Hashida, M.; Nomura, T.; Harashima, H.; Yamasaki, Y.; Kataoka, K.; Yamashita, A.; Katoono, R.; Yui, N. Chem. Phys. Chem. 2012, 13, 1161. http://dx.doi.org/10.1002/cphc.201100800 PMid:22383277

126. Wang, P.-J.; Wang, J.; Ye, L.; Zhang, A.-Y.; Feng, Z.-G. Polymer 2012, 53, 2361. http://dx.doi.org/10.1016/j.polymer.2012.03.060

127. Hagiwara, T.; Murano, Y.; Watanabe, Y.; Hoshi, T.; Sawaguchi, T. Tetrahedron Lett. 2012, 53, 2805.

128. Hagiwara, T.; Yamazaki, M.; Suzuki, T.; Sawaguchi, T.; Yano, S. Polymer 2011, 52, 5426. http://dx.doi.org/10.1016/j.polymer.2011.10.022

129. Heine, J.; Schmedt auf der Gunne, J.; Dehnen, S. J. Am. Chem. Soc. 2011, 133, 10018. http://dx.doi.org/10.1021/ja2030273 PMid:21657228

130. Bunha, A.; Tria, M. C.; Advincula, R. Chem. Commun. 2011, 47, 9173. http://dx.doi.org/10.1039/c1cc13162a PMid:21748185

131. Fioravanti, G. Current Org. Synth. 2012, 9, 199. http://dx.doi.org/10.2174/157017912799828996 
132. Balzani, V.; Credi, A.; Venturi, M. In From Non-Covalent Assemblies to Molecular Machines, Eds. Sauvage, J. P.; Gaspard, P. Wiley-VCH: New York, 2011; p 159.

133. Barin, G.; Coskun, A.; Friedman, D. C.; Olson, M. A.; Colvin, M. T.; Carmielli, R.; Dey, S. K.; Bozdemir, O. A.; Wasielewski, M. R.; Stoddart, J. F. Chem. Eur. J. 2011, 17, 213. http://dx.doi.org/10.1002/chem.201002152 PMid:21207618

134. Prabhakaran, P.; Priya, G.; Sanjayan, G. J. Angew. Chem. Int. Ed. 2012, 51, 4006. http://dx.doi.org/10.1002/anie.201107521 PMid:22374711

135. Li, Z.-T.; Zhang, K.-D.; Shi, Z.-M.; Wang, L.; Zhou, C.; Lu, B.-Y. Pure Appl. Chem. 2012, $84,965$. http://dx.doi.org/10.1351/PAC-CON-11-08-20

136. Zhang, K.-D.; Zhao, X.; Wang, G. T.; Liu, Y.; Zhang, Y.; Lu, H. J.; Jiang, X. K.; Li, Z. T. Angew. Chem. Int. Ed. 2011, 50, 9866.

http://dx.doi.org/10.1002/anie.201104099 PMid:21887826

137. Silvi, S.; Venturi, M.; Credi, A. Chem. Commun. 2011, 47, 2483. http://dx.doi.org/10.1039/c0cc03829f PMid:21135934

138. Ruangsupapichat, N.; Pollard, M. M.; Harutyunyan, S. R.; Feringa, B. L, Nat. Chem. 2011, 3,53 .

http://dx.doi.org/10.1038/nchem.872 PMid:21160518

139. Ferrand, Y.; Gan, Q.; Kauffmann, B.; Jiang, H.; Huc, I. Angew. Chem. Int. Ed. 2011, 50, 7572.

http://dx.doi.org/10.1002/anie.201101697 PMid:21717537

140. Gan, Q.; Ferrand, Y.; Bao, C.; Kauffmann, B.; Grelard, A.; Jiang, H.; Huc, I. Science 2011, 331,1172 .

http://dx.doi.org/10.1126/science.1200143

PMid:21385710

\section{Authors' Biographies}

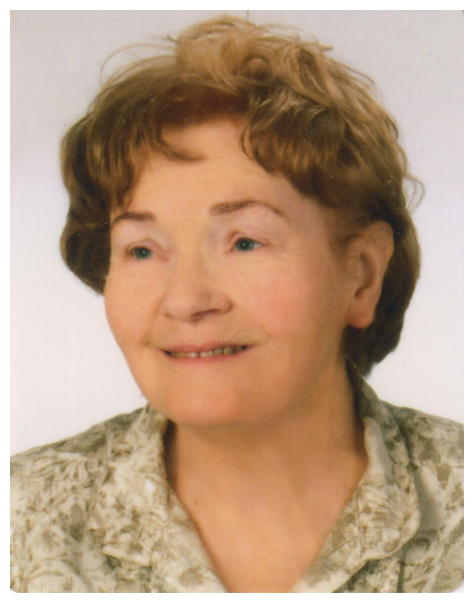

Wanda Sliwa graduated from Wrocław University of Technology, Poland where she became an associate professor. After a year research at Université Paul Sabatier à Toulouse, France, she moved to Jan Dlugosz University of Czestochowa, Poland, where she has been Professor of Chemistry since 1990, as well as being a vice-rector, head of the Organic Chemistry Department and director of the Institute of Chemistry. She is author or coauthor of four books and 16 monographs, around 350 papers and ten patents, and has received several awards for scientific 
and pedagogical achievements. Her research concerns azaaromatic compounds and supramolecular chemistry.

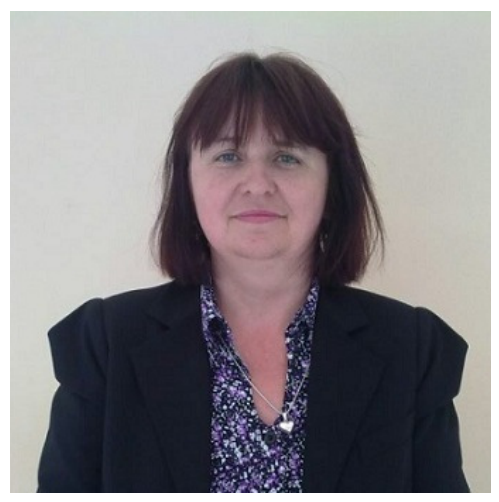

Malgorzata Deska graduated from Pedagogical University of Częstochowa, Poland, she received there M.Sc. degree in 1990. Since this time she works at Jan Długosz University (formerly Pedagogical University) of Częstochowa in Organic Chemistry Department and in Biochemistry Department. In 2004 she obtained her PhD at Technical University of Krakow, the doctor thesis concerned physicochemical properties of diazaphenanthrenes. She has published 15 papers in refereed journals, 5 communications to scientific meetings and is a coauthor of a book. The research interests of Dr Malgorzata Deska are connected with chemistry of heterocyclic compounds, cyclodextrins and calixarenes.

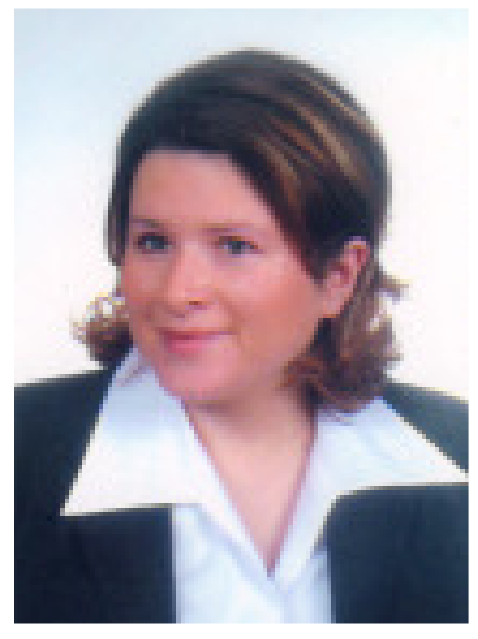

Jolanta Kozlowska graduated from Pedagogical University of Czestochowa, Poland and received there the Chemistry M.Sc. degree in 1997. In 2000 she obtained the Mathematics M.Sc. degree at Opole University (Poland). She works at Jan Dlugosz University (formerly Pedagogical University) of Czestochowa, in Institute of Chemistry, Environment Protection and Biotechnology. Dr. Jolanta Kozlowska obtained PhD at Technical University of Wroclaw; her doctor theme concerned membrane processes with the use of macrocycles. She is coauthor of 16 papers in refereed journals, and of 20 conference communications. Her research is connected with application of membrane technics in separation of metal ions. 